\title{
Time-Dependent Biofouling Growth Model for Predicting the Effects of Biofouling on Ship Resistance and Powering
}

\author{
Dogancan Uzun $^{\mathrm{a}^{*}}$, Yigit Kemal Demirel ${ }^{\mathrm{a}}$, Andrea Coraddu ${ }^{\mathrm{a}}$, Osman Turan ${ }^{\mathrm{a}}$ \\ ${ }^{a}$ Department of Naval Architecture, Ocean and Marine Engineering, University of \\ Strathclyde, 100 Montrose Street, Glasgow, G4 OLZ, UK \\ *corresponding author; e-mail: dogancan.uzun@strath.ac.uk, phone: +44(0)7933188524
}

\begin{abstract}
This paper presents a time-dependent biofouling growth model which enables prediction of the effect of biofouling on ship resistance and powering for day-to-day evaluation. Initially, antifouling coating tests data were employed in the model to predict coating performance over time by considering the ship operating profile and shipping route. Based on the equivalent sand roughness heights found in literature, time-dependent biofouling growth predictions were turned into equivalent sand roughness heights. Then, the provided roughness functions for different surface conditions as well as the predicted equivalent sand roughness heights were employed in Granville's similarity law scaling to investigate the effect of roughness on full-scale ship resistance.

Then, the model was tested through one-year long operation data of a $176 \mathrm{~m}$ long tanker measured by on-board systems to validate the model. Percentage increase in frictional resistance of the $176 \mathrm{~m}$ long tanker was predicted to be $\sim 32 \%$. Results were compared and validated using real data. Secondly, a case study was performed using noon-report data for 3years operation of a $258 \mathrm{~m}$ long crude-oil carrier. Increase in effective power of the ship was predicted to be $\sim 25 \%$. Finally, the predictions were compared to ship performance reports that were provided by the ship operator.
\end{abstract}

\section{Keywords}

Time-dependent biofouling; Antifouling coating field tests; Maintenance schedule decision-support tool, Added resistance prediction; Ship operating profile 


\section{INTRODUCTION}

Marine biofouling is known as the undesired accumulation of living organisms on immersed surfaces. It is a complex phenomenon that is affected by various physical and environmental factors. These environmental factors include but are not limited to water temperature, salinity, $\mathrm{pH}$, nutrient abundance, the velocity of water flow, water depth, and light. Physical factors mainly depend on surface properties including micro texture, surface charge, wettability, roughness, colours and contours (Gregory and Bhushan, 2012; McDonald et al., 2009; Woods Hole Oceanographic Institute, 1952).

The International Maritime Organization (IMO) identified marine biofouling as one of the primary problems from both economic and ecologic points of view. It threatens the ecological balance of world seas by transferring invasive aquatic species and causes a reduction in hydrodynamic performance of ships, which in turn increases fuel costs and greenhouse gases (GHG) emissions.

A number of studies investigated the effects of biofouling on ship performance in the literature. Milne (1990) stated that fuel consumption increases by up to $40 \%$ unless precautions are taken to prevent fouling. Schultz (2007) reported that the presence of slime alone required a $21 \%$ increase in shaft power, compared to an otherwise identical slime-free frigate, whereas heavy calcareous fouling led to an $86 \%$ increase in shaft power requirements at 15 knots. Several studies (Kempf, 1937), (Schultz and Swain, 2000), (Schultz et al., 2011), (Kempf, 1937), (Turan et al., 2016), (Monty et al., 2016) have been carried out to highlight the effect of biofouling on ship resistance and powering. Munk et al. (2009) presented added resistance diagrams showing an increase in frictional resistance against ship operation time due to biofouling by using software which processes performance data collected from the ship. Furthermore, the study stated that the fuel cost of ships increase at least $10 \%$ on average when the ship hull is lightly fouled, and up to $35 \%$ when the ship hull is heavily fouled. More recent evidence of Demirel et al. (2017a), Demirel et al. (2017b), Owen et al. (2018) and Song et al. (2019) showed that biofouling attachment on a ship hull surface or propeller surface caused severe efficiency losses and thereby increases in ship power.

To minimise these effects, IMO introduced a biofouling management plan/guideline and strongly suggested that its application should come into force for ships. The biofouling management plan shows that choosing the appropriate antifouling system is the key decision and this process needs to be supported by technical advisors. The factors that need to be considered while choosing an antifouling system are defined as follows: expected drydocking periods, ship speed, ship operation profile, ship type and legal requirements (IMO, 2011).

As presented in Chambers et al. (2006) several methods are currently being used to mitigate biofouling, however, for now, the best known and useful approach is the fouling control coatings in protecting ships against biofouling accumulation (Tezdogan and Demirel, 2014). The main types of coating technologies are Self-Polishing Copolymer (SPC), Controlled Depletion Polymer (CDP), conventional paints and Foul-Release (FR) coatings. Although these coatings have different working mechanisms, they can be categorised as biocidal and non-biocidal coatings. Products of biocidal technologies which are SPC, CDP and conventional type of coatings release copper ions and booster biocides to prevent biofouling on the ship hull. SPC, CDP, and conventional type coatings are effective against invertebrate organisms, but SPC type paints have longer maintenance spans ( $\sim$ years) compared to CDP ( $\sim 3$ years) and conventional paints ( 12-18 months). The SPC technique uses a chemical reaction through hydrolysis of heavy metals by also smoothing itself whereas CDP technique has a soluble matrix physically dissolving in water by releasing biocide. However, it underperforms during stationary times of ships and its self-smoothing feature is not as good 
as SPC type paints (Chambers et al., 2006). The foul-release coatings, with an environmentally friendly approach, do not release toxicant materials but reduce attachment strength of fouling organisms and release attached organisms when the ship is underway. Foul-release coatings have a very different surface texture which in general leads to lower added resistance for a newly applied coating than is the case for CDP and SPC coatings (Anderson (Anderson, 2003 \#80) et al. 2003) However, this type of coatings can clean itself at high speeds ( $>15$ knots) and is effective for ships which have high activity operating profile. Otherwise, they need to be cleaned frequently. Besides, these paints are prone to abrasion damage because of their surface features (Dafforn et al., 2011).

In general, an antifouling coating's performance is tested through various ageing tests for more than ten years before being available in the market (Kiil and Yebra, 2009). These ageing tests can be separated into two groups: laboratory tests and field tests. The standard testing process starts with short-term laboratory tests to evaluate the formulation/material used in the paint and follows with medium-term (months) tests to measure the polishing and leaching performance of the coating. The products which show satisfactory performance are transferred to field tests which are comparatively long-term tests, including static tests, dynamic tests, and ship tests. Paint manufacturers have to rely on these long-term tests for checking paint performance on a regular period since a potential mistake in paint design would cause high-cost penalties. The static tests conducted by immersing the coated test panels into natural seawater simulate the conditions that coating would be exposed to during the ship's idle times. Test sites are usually selected from the regions as diverse as possible, such as relatively cold, temperate and warm environments to test coating performance. Dynamic tests, additionally aim to provide shear stress on coating plates immersed in natural seawater usually via a rotating mechanism (i.e., rotating drum) for evaluating the performance of the coating in dynamic conditions. These tests are useful to determine the polishing rates of self-polishing coatings and releasing ability of foul-release coatings (Sánchez and Yebra, 2009). An approach of combined static and dynamic tests, and also ship tests were proposed as a more realistic way to simulate antifouling coating performance under real conditions (Lindholdt et al., 2015; Swain et al., 2007). Despite the fact that the ship tests bring potential higher accuracy, implementation of these techniques poses various problems associated with the preparation of a large amount of paint, coordination with the ship owner and regular monitoring of paint performance on the ship hull. Even though dynamic testing is reasonably cheap compared to ship tests, it is still more expensive compared to static tests as the test rig needs motion, which means perpetual power usage. Therefore, as stated in Sánchez and Yebra (2009) medium and long-term ageing tests will be the primary source of information about antifouling coating performance in the future and can provide required data for mathematical biofouling growth models.

Although numerous products are available within the different coating technologies given above, there is no scientific selection mechanism for the best antifouling coating for the specific ship in question. Therefore, an antifouling coating selection is commonly made through recommendations by non-experts, the information provided by the manufacturer and communication with sales personnel as well as the availability of the coatings in the region where the ship is repaired or maintained. Thus, there is a strong possibility that this situation may result in the wrong coating selection (Swain et al., 2007).

In total, all antifouling precautions cost around 1.5 billion USD per year for the world fleet which is equivalent to approximately $5 \%$ of the total fuel-oil cost for a year. Since there is no scientifically settled approach, it is hard to decide which type of hull protection is appropriate and vessel owners have their particular strategy to deal with marine fouling based on personal experience (Munk et al., 2009). 
A tailor-made condition assessment should be made by considering the factors mentioned above, and this assessment requires a time-dependent biofouling growth model to estimate and mitigate the losses due to biofouling. This model can be used as a decision support-tool, regarding the effect of biofouling roughness on ship frictional resistance and hence the increase in power requirement as well as deciding the appropriate maintenance schedule. In this study, a simplified time-dependent biofouling growth model was proposed based on the long-term antifouling field test data for estimating the increase in frictional resistance and powering due to marine fouling on the ship hull. First, fouling ratings (FR) and surface coverages (SC) for calcareous type fouling were converted into the equivalent sand roughness heights in accordance with the data provided by Schultz (2007) and Uzun et al. (2017). Then, the equivalent sand roughness heights were employed in Granville's similarity law scaling process (Granville, 1958) (Granville, 1987) with the provided roughness functions of corresponding fouling conditions to calculate the increases in frictional resistance. Finally, the increases in effective power of the ship due to the increase in frictional resistance were calculated for calm water conditions.

First, the developed model was tested and validated using a one-year long operation data of a 176-meter handy-max oil tanker. The fouling ratings, surface coverages for calcareous type fouling, increases in frictional resistance and powering were predicted during this time. Then, the results were validated through comparisons on real-world operation data, acquired via on-board data acquisition system and that were filtered to only retain those data recorded in calm water conditions

Besides, a case study was performed using a three-year-long operation data of $258 \mathrm{~m}$ crude oil carrier. The same analyses were conducted for this case, and increases in effective power were predicted and then compared to the ship performance report provided by a ship performance analysis company. The comparison showed a very good agreement between the results predicted by the model and the results in the company report.

The paper is organised as follows: in Section 2, the modelling approach is presented. In Section 3, the validation of the model is explained. First, the developed model is tested using a year's worth of real-world data of a vessel and then results are compared with the measured real power data. In Section 4, the model is used on a case study and results are presented in comparison with a company report. Finally, the results of the study are discussed together with the assumptions, limitations and further work in Section 5.

\section{MODELLING APPROACH}

\subsection{General perspective}

The main aim of this study is to predict the increases in ship frictional resistance and powering due to the accumulation of biofouling on a ship hull during a selected ship operation period. To achieve these goals, two complementary models, namely, the timedependent biofouling growth model and the added frictional resistance prediction model were developed. The first model, predicts biofouling growth by taking idle times into account during a ship operation period based on the acquired field test data for a specific antifouling coating which the ship is painted with. The second model then estimates increases in ship frictional resistance and powering based on the predicted biofouling condition for the ship under consideration. The developed models are explained in detail in the following sections. 


\subsection{Ideal Biofouling Growth Model}

The relation between environmental conditions and biofouling growth is investigated through laboratory or field experiments. Marine biofouling growth on a specified surface, with an unlimited experimental data, would have been formulated as in relation with the parameters listed in Eq. 1 (Woods Hole Oceanographic Institute, 1952) (Lehaitre et al., 2008).

$$
B G=f_{1}\left(S S T, p s u, p H, v, I, S, t, m_{t}, \sigma, \theta_{c}, R_{t}, \eta_{c}\right)
$$

where BG is biofouling growth, $S S T$ is seawater surface temperature, $p s u$ is salinity (dissolved salt content of the water), $p H$ is acidity, $v$ is speed of the water flow, $I$ is light intensity, $S$ is concentration of nutrients, $t$ is time of the exposure to water, $m_{t}$ is microtexture of surface, $\sigma$ is surface potential, $\theta_{c}$ is the contact angle which is a measure of wettability, $R_{t}$ is a roughness parameter and $\eta_{c}$ is an antifouling coating performance parameter (efficiency of the antifouling coating including performance of chemical contents and leaching rate). Although it is not well-established, surface colour and contour have various effects on biofouling growth as well (Gregory and Bhushan, 2012).

Despite the fact that there is a substantial amount of experimental and modelling studies on biofouling growth, these studies rather have been focused on a single type of biofouling growth or the effect of few parameters (Darvehei et al., 2018). Therefore, a comprehensive biofouling growth model that predicts biofouling growth rate under varying environmental conditions does not exist. There are significant barriers in the path to a successful comprehensive biofouling growth model. This sort of comprehensive growth model considers the effects of various parameters shown in Eq. 1 and validation of the model becomes more complicated as the number of parameters increase. It is of note that validation of the model with many parameters needs large data collection which requires extensive time and resources.

Moreover, the environmental conditions, even on the same day, show differences for the outdoor experimental studies and these regularly fluctuating parameters make prediction difficult for short term models. However, if the model is designed for a long term, these issues can be simplified. For instance, the effect of seasonal changes on biofouling growth in a particular location can be averaged through 2-3 years long field tests.

Biofouling growth models with this amount of parameters are not useful for the end-users such as naval architects, ship operators and ship owners. A simplified long term model with a limited number of parameters would be applicable and easier to validate. This model may be helpful for end-users as a preliminary attempt of a decision support-tool by providing a prediction on biofouling growth as well as the increase in power requirements due to this growth.

\subsubsection{Simplification of the ideal model}

The authors proposed the following simplifications over the ideal formulation to develop a simplified biofouling growth model for ships. A list of simplifications and the development of the simplified equation were presented together with the explanations supported by the researches in the literature. 
The conducted simplifications are;

- $\quad$ Surface properties $\left(m_{t}, \sigma, \theta_{c}, R_{t}\right)$

The surfaces properties such as $m_{t}, \sigma, \theta_{c}$ and $R_{t}$ affect biofouling on the surface. Hydroids, bryozoans and ascidians search the surface for grooves, pits, cracks, and crevices in the micro-texture $\left(m_{t}\right)$ to settle in for protection against strong water flow (Fingerman et al., 1999) (Railkin, 2004). Microfouling organisms are in search of a hollow that they can settle in for maximum protection and attachment points which enable them to have higher adhesion strength (Scardino et al., 2008).

The extracellular polymeric substance (EPS) flows into the crevices formed by surface roughness $\left(R_{t}\right)$. This enables organisms to have strong bio-adhesion on the rough surfaces whereas adhesive contacts only on surface asperity peaks on the smooth surfaces cause low bio-adhesion strength (Gregory and Bhushan, 2012). . The maximum peak-to-through roughness height, in general, varies between 30 and 150 microns for newbuilding applications depending on the quality of the application and the type of coating. For example, the maximum peak-to-through roughness height is expected to be in a range between 30 and 129 for SPC type coatings whereas this range changes to 7 and 85 for FR coatings.(Howell and Behrends, 2006) (Candries, 2001).

Surface potential (surface charge) $(\sigma)$ also influences the attachment of microorganisms. Kerr et al. (1998) showed that applied negative surface potential (between -65.4 and $-230.4 \mathrm{mV}$ ) reduces bacterial fouling whereas positive surface potential $(34.5-234.9 \mathrm{mV})$ increased the percentage of settlement compared to the uncharged reference surface. However, this amount of change in surface potential cannot occur unless it is applied from outside, which is not practical for antifouling coatings on the ship hulls.

The wettability of a surface is assessed by the contact angle $\left(\theta_{c}\right)$; where the contact angles are less than $10^{\circ}$, the surface behaves super-hydrophilic, which shows high wettability and high surface energy. On the other hand, contact angles over $150^{\circ}$ are classed as super-hydrophobic surface and exhibit low wettability and low surface energy. Despite the fact that microorganisms prefer to attach on hydrophilic surfaces, this may change according to the type of specie i.e.; hydrophobic surfaces are more suitable for Ulva linza (Gregory and Bhushan, 2012). Polyurethane-based antifouling coating formulations, which include biocides exhibit stable behaviour in terms of wettability, whereas silicone based coatings may go hydrophilic in time (Silva et al., 2019).

As the intention of the model is to predict biofouling growth on a particular specific coating that applied on a ship, the authors believe that long term lab and field test data would capture the effects of surface properties on biofouling growth. It is assumed that the applied coating type will not change during the ship operations for the foreseen duration. The effects of environmental factors (temperature, salinity etc.) on coating surface properties such as roughness and texture were ignored. However, the authors believe that the effect of changing surface properties can be measured by the field tests. Therefore, these effects were also taken into account and represented by the antifouling coating parameters. The only surface parameter that substantially 
changes with the environmental conditions is the $\eta_{\mathrm{c}}$ (antifouling coating performance parameter) and it will be one of the main parameters that the model stands on.

\section{- Light intensity $(I)$}

Light intensity and light spectrum are parameters that strongly affect plant type biofouling community from micro algae to weeds. It is associated with the water depth in the models presented in the literature (Darvehei et al., 2018). Photosynthetic macrofouling types, mostly algae, are generally common in the 0-40 meter range where is rich in nutrients and with high light level. However, other types of organisms (mussels, barnacles, tubeworms, etc.) which get their energy from the sources in the sea, can grow at deeper waters without having affected by light intensity (Lehaitre et al., 2008). It should be noted that as the ship draft ranges between $5 \mathrm{~m}$ and $20 \mathrm{~m}$ for large merchant vessels, it can be assumed that light intensity will not be varying by a large extent. Therefore light intensity and light spectrum of the locations are accepted as the same with the places where the biofouling field test is conducted.

- Concentration of nutrients and water flow velocity $(S, v)$

Nutrient abundance is critical for marine fouling from biofilm formation to macro fouling as all living organisms need food to sustain their lives. At this point nutrient abundance is also connected with seawater flow rate and closeness of location to shore. Coastal waters are generally richer than oceanic waters in terms of nutrient abundance due to human-based discharges (Lehaitre et al., 2008). Therefore, as ship closes to shores, biofouling growth accelerates. With the available data, biofouling growth is modelled when the ship stays at ports at stable water velocity, and the concentration of nutrients is accepted as same for every port.

- $\mathrm{pH}$

Due to the lack of data about the effect of $\mathrm{pH}$ on total biofouling growth rather than on a particular species, it is not possible to model responses of $\mathrm{pH}$ changes. However, as stated in Cullimore (1999), Kroeker et al. (2013) and Darvehei et al. (2018) pH levels between 6.5 to 10 are suitable for an extensive range of biofouling organisms. Furthermore, as shown in Takahashi et al. (2014) $\mathrm{pH}$ values of seawater range from 7.74 to 8.4 on a global scale. Considering this limited change in $\mathrm{pH}$ values on world seas, effects of $\mathrm{pH}$ on biofouling growth were simplified for this model.

- Salinity (psu)

Salinity is a decisive parameter for the growth of biofouling organisms and different types of biofouling have varying reactions to salinity changes (Thiyagarajan et al., 2003) (de Castro et al., 2018). Despite the importance of salinity, to the author's knowledge and as stated in (Darvehei et al., 2018), no mathematical model is covering this effect. The reasons for this might be that the salinity studies in the literature (Qiu and Qian, 1998) aim to observe salinity tolerances of biofouling organisms instead of modelling the effect of salinity on biofouling growth rate. In addition, world seas' salinity value ranges between 30-36 psu and biofouling organisms' salinity tolerance covers this range.

Based on the simplifications explained, the most dominant parameters were based on the antifouling coating performance parameter and exposure time to seawater. Based on the given assumptions, Eq. 1 was simplified and turned into Eq. 2 to model the biofouling growth on ships for the idle time periods at each port during a ship operation period. Therefore, 
without an intention of following the physiologically detailed mechanistic approach for formulating effects of each parameter at cell scale, a simplified growth model was developed depending on the exposure time and antifouling coating performance parameter as shown by Eq.2.

$$
\begin{aligned}
& B G=f_{2}\left(t, \eta_{c}\right) \\
& \eta_{c}=g(\Delta S S T)
\end{aligned}
$$

where $t$ is the exposure time and $\eta_{\mathrm{c}}$ is the antifouling coating performance parameter, and $\triangle S S T$ is the change in sea surface temperature. It is important to note that coating performance exhibits differences according to the geographical region. This can be attributed to the fact that temperature has the dominant effect on the biofouling growth as stated in Thiyagarajan et al. (2003), Qiu and Qian (1998), Villanueva et al. (2011), Farhat et al. (2016) and Lord (2017). Therefore, the change in sea surface temperature ( $\triangle S S T)$ was used as a parameter to predict the changes in coating performance, as shown in Eq.3.

\subsection{Development of a Time-Dependent Model for an SPC Type Antifouling Coating}

\subsubsection{Field test data and analysis}

Extensive static field tests data were provided by a paint company for an SPC type antifouling coating paint product. The tests were conducted from one to three years in two regions, including Mediterranean and Equatorial regions, which are environmentally diverse in terms of geographical features. In these field tests, biofouling growth on coated and immersed plates was assessed according to ASTM ASTM D6990-05 (2011), and ASTM ASTM D3623-78a (2012) performance standards and evaluations were recorded for mainly three types of biofouling accumulations through monthly observations. These analyses were then supported with image processing, which enables obtaining colour contrast and having a more accurate quantification of the fouled area, number, and size of the attached fouling organisms.

Based on the image analyses, the fouling coverages on the panels were rated by coverage rating based on coverage areas similar to Braun-Blanquet (1932) scale method. The coverage ratings with equivalent covered surface areas were presented in Table 1.

Table 1 The coverage ratings with an equivalent covered surface adapted from (Silva et al., 2019)

\begin{tabular}{ll}
\hline $\begin{array}{l}\text { Coverage } \\
\text { Rating }\end{array}$ & $\begin{array}{l}\text { Covered } \\
\text { Area }(\%)\end{array}$ \\
\hline 0 & 0 \\
1 & $0-2$ \\
2 & $3-5$ \\
3 & $6-25$ \\
4 & $26-50$ \\
5 & $51-100$ \\
\hline
\end{tabular}

Antifouling field tests results were analysed by a paint company and biofouling accumulations on the test panels were categorised into three main groups: slime, non-shell organisms and calcareous type fouling. The maximum rating of each biofouling group varies 
considering their hydrodynamics effect on frictional drag. These types along with their maximum ratings $(a)$ include;

- Slime: including absorbed inorganic and organic matter, trapped silt and detritus and other unidentified slimes (Rating 0-20).

- Non-shell organisms (shorter than 5mm): Plants, soft-bodied organisms, weed, very isolated (limited) barnacle accumulation (Rating 0-50).

- Calcareous type fouling (higher than 5mm): Barnacles, mussels, tubeworms, etc.(Rating 0-100)

A fouling rating parameter, named antifouling performance index (API) was developed independently to measure the antifouling performance of coated ship hulls by the paint company. The developed index aims to measure the effects of major foulants on the antifouling performance in dynamic conditions (Silva et al., 2019). The API formula given in Silva et al. (2019) was adapted to express the fouling rating (FR) in this study, as shown in Eq.4. The slight difference between the FR and API is that the clean surface is represented by 0 for FR, whereas it is represented by 100 for API.

$$
\begin{gathered}
F R=(0.2 \times \text { Area covered by slime } \\
+0.5 \times \text { Area covered by non }- \text { shell organisms shorter than } 5 \mathrm{~mm} \\
+15 \times \text { area covered by calcareous fouling higher than } 5 \mathrm{~mm})
\end{gathered}
$$

where the area covered by fouling organisms is taken from the upper limit for the equivalent coverage rating.

The model aims to design a simplified long term model by averaging short term seasonal effects using 2-3 years long field data. The approach behind the model was to design it in three steps including delay, growth, and saturation at maximum rating point. Considering this approach and in the light of previous biologic models, it was envisaged that the biologic growth model tends to follow a sigmoid function. In this study, however, it was observed that a Gaussian type fit is effective to represent the correlation between fouling rating and time. The Gaussian function is similar to the sigmoid function in nature, but it provides better accuracy with less parameters. Although the Gaussian function graph is a symmetric bellshaped curve, in this study, the half-bell curve was used to satisfy the saturation phase at the maximum point. Therefore, once the rating reaches a maximum point, the fit is fixed on this point to account for the fact that growth and its hydrodynamic effects are limited. It is accepted based on the assumption that the hydrodynamic performance of the surface will gradually deteriorate in time. 


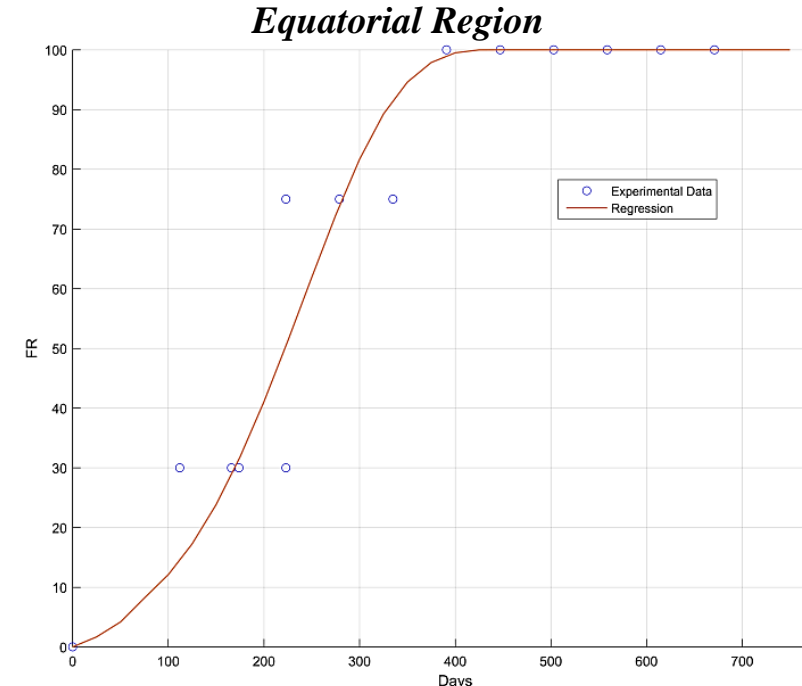

Fig. 1a. Type A fouling growth according to immersed time in the Equatorial region

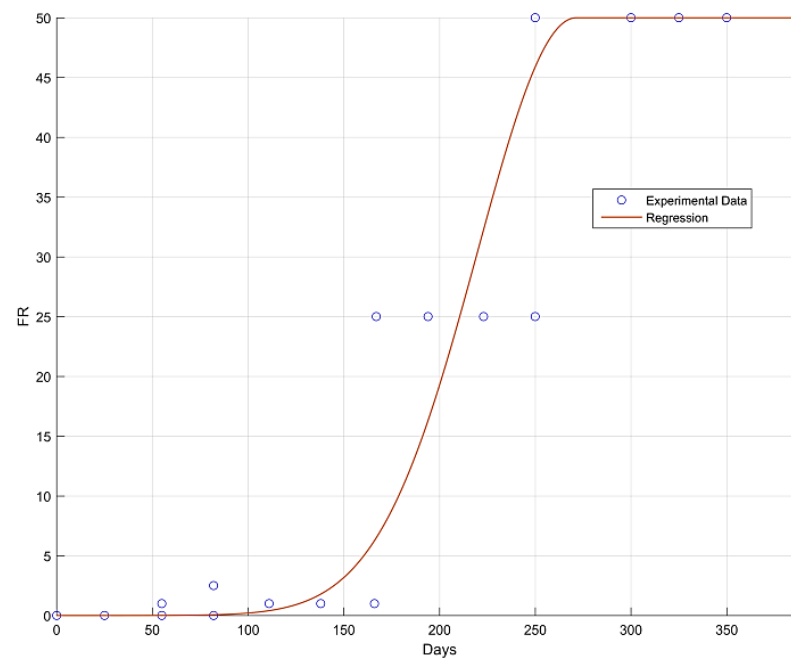

Fig. 1b. Type B fouling growth according to immersed time in the Equatorial region

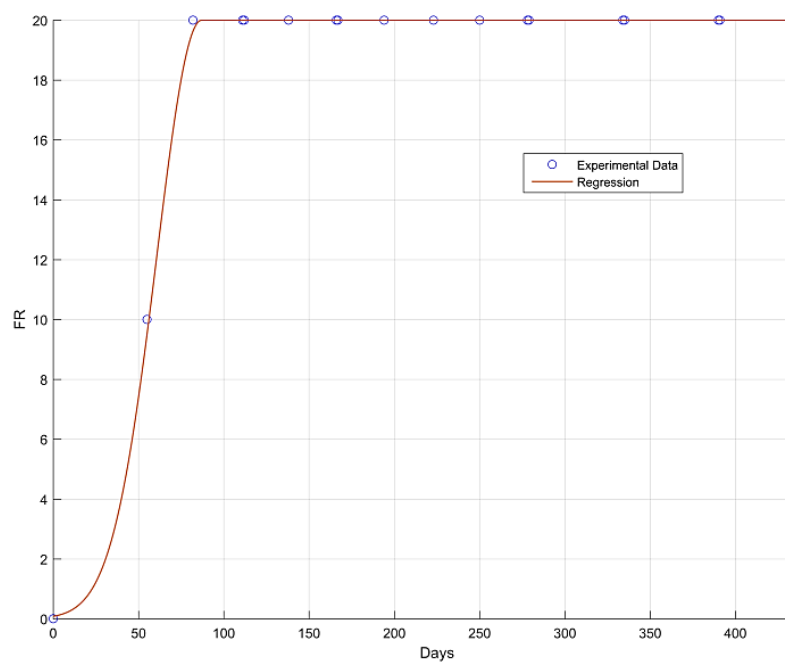

Fig. 1c. Type $\mathrm{C}$ fouling growth according to immersed time in the Equatorial region

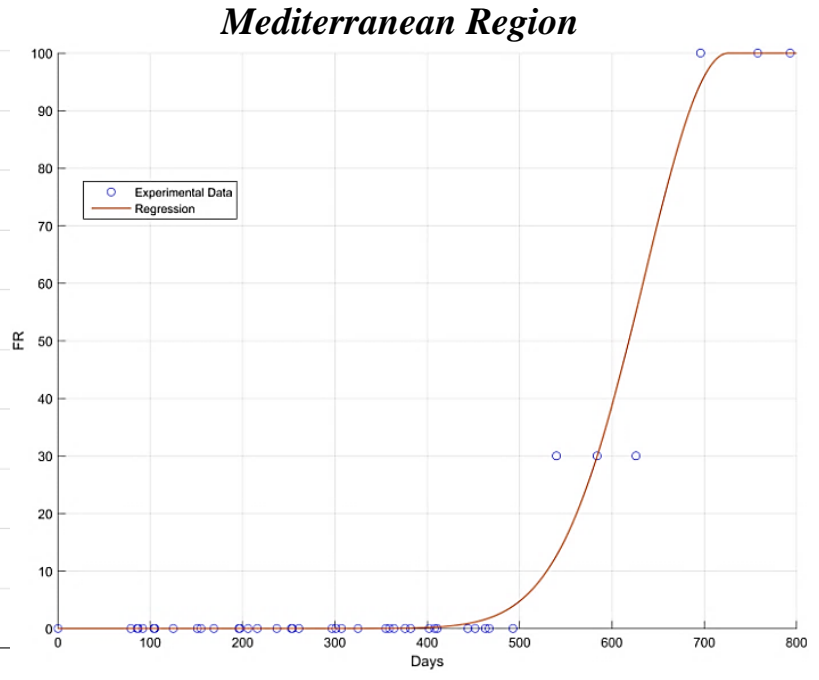

Fig. 2a. Type A fouling growth according to immersed time in Mediterranean region

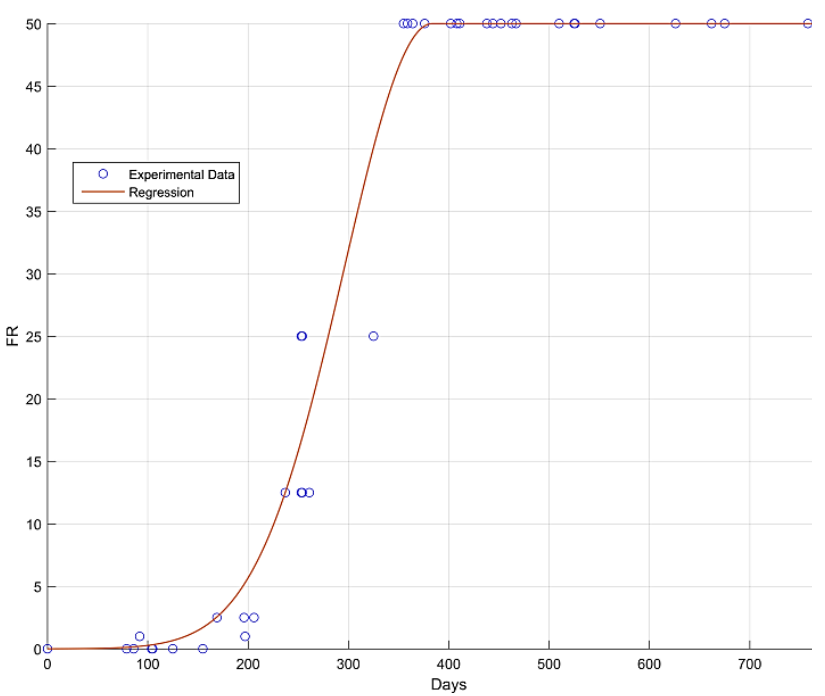

Fig. 2b. Type B fouling growth according to immersed time in Mediterranean region

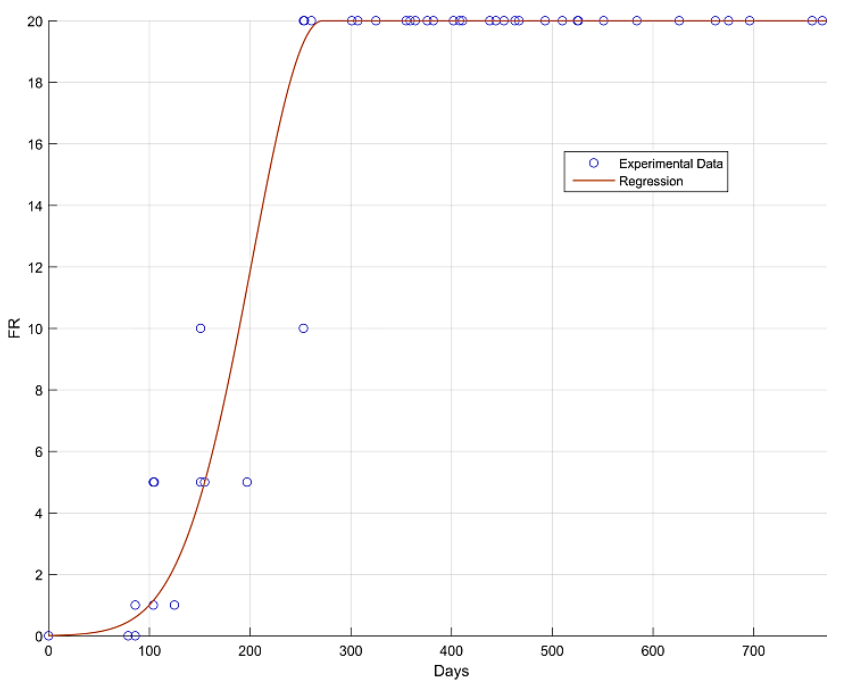

Fig. 2c. Type $\mathrm{C}$ fouling growth according to immersed time in Mediterranean region 
Figs.1a, 1b, 1c and Figs. 2a, 2b, 2c illustrate the rating data for three types of fouling obtained from the field tests conducted over varying periods of time at Equatorial and Mediterranean regions, respectively. The Gaussian function shown in Eq. 5 was fitted on the data, as illustrated in the figures above. However, during the growth phase, it was observed that there are deviations between the Gaussian fit and the data points as similarly reported in Breur (2001). This deviation can be attributed to the fact that seasonal changes occur during the year since field tests are conducted via several replica test panels which are immersed at varying seasons of the year. Therefore, the replica panels immersed in the warm seasons show rapid biofouling growth compared to those, which were immersed in the cold seasons.

$$
F R=a e^{\left[-\left(\frac{t-t_{0}}{\tau}\right)^{2}\right]}
$$

where $F R$ is the rated biofouling growth, $a$ is the maximum rating, $t$ is the sum of idle time, $t_{0}$ is the time that rating reaches to the maximum point and $\tau$ is the half-width of the bell curve. $t_{0}$ and $\tau$ are taken as coating performance parameters $\left(\eta_{\mathrm{c}}\right)$ since they define the time in which fouling rate reaches the maximum point and the time span of growth after the delay time. When the ship spent idle time in an arbitrary region on the route, $t_{0}$ and $\tau$ are calculated through Eq.5 separately.

Although there are deviations between the trend and data points due to seasonal changes, the model is able to predict the general trend in the data. As the main aim of the model is to average short term effects including seasonal changes on biofouling growth by using long term field test data, the Gaussian fit is successfully employed in order to average seasonal changes on the biofouling growth. The coating performance parameters $\left(t_{0}, \tau\right)$ were determined via Eq.5 fitted on the data as shown in Table 2 for each type of fouling at both regions.

Table 2 Antifouling coating performance parameters for each type of fouling

\begin{tabular}{|c|c|c|c|c|}
\hline Type of fouling & Location & $t_{0}$ & $\tau$ & \multirow{7}{*}{ 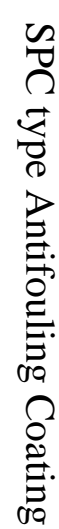 } \\
\hline Calcareous fouling & Equatorial & 379.4 & 187.2 & \\
\hline (Type A) & Mediterranean & 726.4 & 129.7 & \\
\hline Non-shell organisms & Equatorial & 271.4 & 73.11 & \\
\hline (Type B) & Mediterranean & 383.5 & 124.4 & \\
\hline Slime & Equatorial & 87 & 37.08 & \\
\hline (Type C) & Mediterranean & 271.9 & 99.31 & \\
\hline
\end{tabular}

In order to predict biofouling growth for each individual idle time period, a specific growth rate for each period needs to be calculated and multiplied with the idle time. "A specific growth rate $(\mu)$ can be calculated by taking partial derivative of Eq.5 with respect to $t$. "The specific growth rate is the speed of the growth, and it varies according to the temperature in conjunction with geographic location. Multiplying the specific growth rate with the idle time gives the fouling growth, which specifically belongs to this individual idle time period. 
Therefore, if this process is repeated for each region where the ship spends idle time, the accumulative fouling rating over a period of operation can be written as given in Eq. 6 .

$$
F R_{t o t}=\sum_{i=0}^{n}\left(\frac{\partial F R}{\partial t}\right)_{i} t_{i}+\left(\frac{\partial F R}{\partial t}\right)_{i+1} t_{i+1} \cdots\left(\frac{\partial F R}{\partial t}\right)_{n} t_{n}
$$

It is important to note that the coverage area of calcareous type fouling is not explicitly expressed in the provided FR equation as shown in Eq. 4. The effect of different SCs, i.e. $25 \%$ and $50 \%$ were neglected. Without a doubt, this condition does not represent reality. Since there is no meaningful rating for calcareous type fouling, it needs to be analysed separately to predict its effect on ship resistance, appropriately.

For this reason, a logistic growth model was developed based on the provided coverage area data from the field test to predict calcareous type fouling surface coverage as a function of time. The logistic function curves were fitted on the field test data for calcareous type fouling in both Equatorial and Mediterranean regions, as explained in Sarkar (2005).

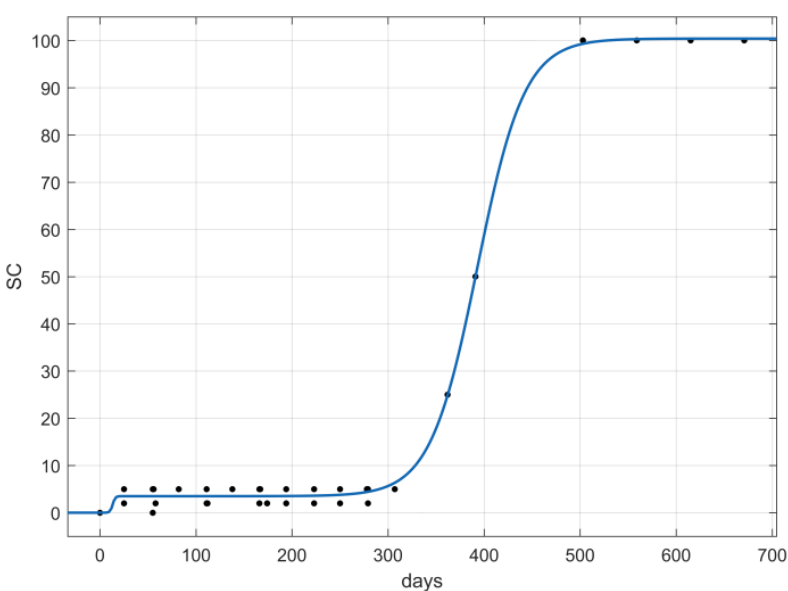

Figure 3a Calcareous type fouling surface coverage respect to time in Equatorial region

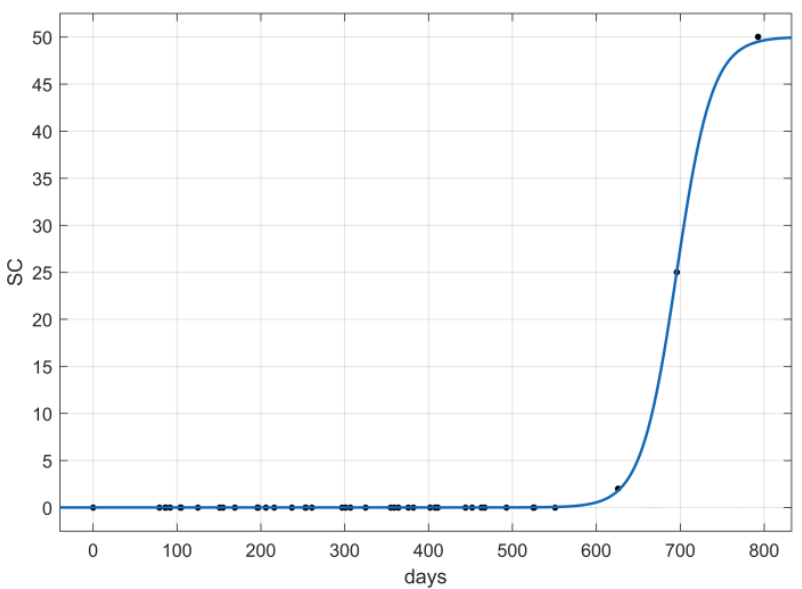

Figure 3b Calcareous type fouling surface coverage respect to time in the Mediterranean region

Fig. 3a and 3b show logistic curves for SC of calcareous type fouling fitted by using Eq.7. Table 2 gives constant values of the curves for both Equatorial and Mediterranean regions.

$$
S C=\frac{P-p}{1+\left(\exp ^{b-c t}\right)}+\frac{d}{1+\left(\exp ^{f-g t}\right)}
$$

where SC is the percentage of surface coverage, $\mathrm{P}, \mathrm{p}, \mathrm{b}, \mathrm{c}, \mathrm{d}, \mathrm{f}$, and $\mathrm{g}$ are logistic curve constants indicated in Table 3, $t$ is the sum of idle times. 
Table 3 Constants of logistic curves

\begin{tabular}{ll}
\hline Equatorial & Mediterranean \\
\hline $\mathrm{P}=100$ & $\mathrm{P}=0.00517$ \\
$\mathrm{~b}=16$ & $\mathrm{~b}=10$ \\
$\mathrm{c}=0.0407$ & $\mathrm{c}=40$ \\
$\mathrm{~d}=3.5$ & $\mathrm{~d}=50$ \\
$\mathrm{f}=10.32$ & $\mathrm{f}=32.81$ \\
$\mathrm{~g}=0.7759$ & $\mathrm{~g}=0.04715$ \\
$\mathrm{p}=3.101$ & $\mathrm{p}=0$ \\
\hline
\end{tabular}

The trend between the SC and time, changes regarding the value of growth parameters which are $b$ for Equatorial region and $f$ for the Mediterranean region. This parameter for an arbitrary region can be predicted similarly by using temperature in Eq.9, as will be explained in Section 2.3.2 below.

By taking the partial derivative of Eq.7 with respect to $t, \mathrm{SC}$ expansion rate can be calculated. Then, multiplying the rate at which SC expands with the idle time gives the calcareous type fouling SC, which specifically belongs to this individual idle time period. In order to predict accumulative SC during the total operation, this process is repeated for each idle time. This can be expressed by Eq.8.

$$
S C_{t o t}=\sum_{i=0}^{n}\left(\frac{\partial S C}{\partial t}\right)_{i} t_{i}+\left(\frac{\partial S C}{\partial t}\right)_{i+1} t_{i+1} \cdots\left(\frac{\partial S C}{\partial t}\right)_{n} t_{n}
$$

\subsubsection{Effect of temperature on biofouling}

The type and SC of biofouling accumulation on an antifouling coating indicates the performance of the coating. Since biofouling growth is strongly dependent to sea surface temperature as indicated in several studies (Crisp and Bourget, 1985; Epelbaum et al., 2009; Farhat et al., 2016; Qiu and Qian, 1998; Thiyagarajan et al., 2003) sea surface temperature is accepted as the dominant parameter for antifouling coating performance as shown in Eq.3. Due to limited availability of field test data, the antifouling coating performance parameters and logistic curve growth parameters $(b$ or $f$ ) for an arbitrary region were interpolated or extrapolated by using Eq. 9, which is based on the obtained performance parameters in the field tests. Eq.9 shows the linear extrapolation or interpolation process for antifouling coating performance parameters.

$$
\eta_{c a}(\Delta S S T)=\frac{\eta_{c y}\left(S S T_{a}-S S T_{x}\right)+\eta_{c x}\left(S S T_{y}-S S T_{a}\right)}{S S T_{y}-S S T_{x}}
$$

Where $\eta_{\mathrm{ca}}$ is the antifouling coating performance parameter at an arbitrary location, $\eta_{\mathrm{cy}}$ is the performance parameter of the coating at the field test location $y, \eta_{\mathrm{cx}}$ is performance parameter of the coating at the field test location $x, S S T_{a}$ is the sea surface temperature at an arbitrary location, $S S T_{y}$ is the sea surface temperature at the location $\mathrm{y}, S S T_{x}$ is the sea surface temperature at the location $x$. 
It should be noted that as the ship moves from one port to another port the model calculates new parameters to be employed in Eq.5 and Eq.7 to predict FR and SC for calcareous type fouling in an arbitrary region on the ship route.

The sea water temperature at any arbitrary location $S S T_{a}$ was predicted via a function based on the latitude degree of the location. This regression was fitted on the data collected from NOAA (National Oceanic and Atmospheric Administration) for average sea surface temperature (Pielke, 2012). The regression for $S S T_{a}$ is presented in Eq.10. It is important to note that differences in SSTs due to longitude changes were neglected as these differences are relatively small compared to those in latitude as given in Bijl et al. (2009).

$$
\operatorname{SST}_{a}=12.5+15\left(\cos \left(\frac{\text { latitude degree }}{28.64}\right)\right)
$$

The authors are aware that reproducing coating performance parameters for the locations in question by using a single parameter (temperature) over the field test data sets at two different locations would not precisely simulate real conditions. Nevertheless, the authors propose a pilot study for attempting a developing simplified biofouling growth model to be utilised for the prediction of ship energy efficiency. Furthermore, it is essential to take into account that the model is flexible to utilise further field data set at extensive locations, and improving the capacity of field test data as it will lead to the more accurate growth model.

\subsection{Added frictional resistance and powering prediction model}

The prediction of the ship frictional resistance and powering due to the change in roughness profile of the ship hull caused by biofouling accumulation has been calculated according the following procedure. The required effective power for a ship can be calculated by Eq.11.

$$
P_{E}=R_{T} V
$$

where $R_{T}$ is total resistance and $V$ is ship speed. The total resistance can be represented as recommended by the ITTC (1978) as shown in Eq.12:

$$
R_{T}=R_{F}+R_{R}+\Delta R_{F}+R_{A A}
$$

where $R_{F}$ is the frictional resistance, the $R_{R}$ is the residual resistance, the $\Delta R_{F}$ is the increase in the frictional resistance due to biofouling, and the $\mathrm{R}_{\mathrm{AA}}$ is the air drag resistance. In terms of total resistance coefficient, $\mathrm{C}_{\mathrm{T}}$, as per Eq 13:

$$
C_{T}=\left(C_{F}\right)\left(1+k_{0}\right)+C_{R}+\Delta C_{F}+C_{A A}
$$

where $\left(1+k_{0}\right)$ is the form factor, $C_{F}$ is the base frictional resistance coefficient, $C_{R}$ is the residual resistance coefficient, $\mathrm{C}_{\mathrm{AA}}$ is the air drag coefficient, and $\Delta \mathrm{C}_{\mathrm{F}}$ is the increase in frictional resistance due to biofouling.

Therefore it is possible to calculate the effective power (Eq. 11) according to Eq.14:

$$
P_{E}=\frac{1}{2} \rho S C_{T} V^{3}
$$


The percentage increase in the frictional resistance and effective power is expressed by Eq. 15 and Eq.16, similar to the one used by Tezdogan et al. (2015) and Demirel et al. (2017b).

$$
\begin{gathered}
\% \Delta R_{T}=100 \frac{\Delta R_{F}}{R_{T}} \\
\% \Delta P_{E}=100 \frac{C_{T_{R}}-C_{T_{S}}}{C_{T_{S}}}=100 \frac{\Delta C_{F}}{C_{T_{S}}}
\end{gathered}
$$

Where $C_{T_{R}}$ is the total resistance coefficient in rough condition, $C_{T_{S}}$ is the total resistance coefficient in a smooth condition which needs to be known in order to calculate $\Delta P_{E}$ for the ship in question. Unfortunately, the calculation of $C_{T_{R}}$ is not an easy task to perform and it requires determination of the drag characteristics of the hull roughness.

Drag characterisation, in other words, determination of roughness functions, of any specified arbitrarily rough surface which is the test surfaces covered with biofouling accumulation in this study, can be revealed thanks to similarity laws of turbulent shear flows. The roughness functions of a rough surface can be determined through direct and indirect methods.

The direct method can be used directly to measure the velocity profile of the boundary layer close to rough surfaces in a flow facility (Granville, 1987). On the other hand, roughness functions can be obtained via indirect methods i.e. by measuring pressure drop in pipe flow (Nikuradse, 1933) or the total drag of flat plates (Granville, 1978) and the torque on rotating disk (Granville, 1982). Even though the methods may show variations in the application, there is a similarity in these procedures, which is plotting the appropriate drag coefficient against the relevant Reynolds number.

Roughness causes a downward shift in the velocity profile which is commonly shown as $\Delta U^{+}$. It is a function of the roughness Reynolds number $k^{+}$defined as the ratio of the roughness length scale $k$ to the viscous length scale as explained in Schultz (2004). The roughness effect on a log-law velocity profile can be seen in Fig.4 (Schultz and Swain, 2000). 


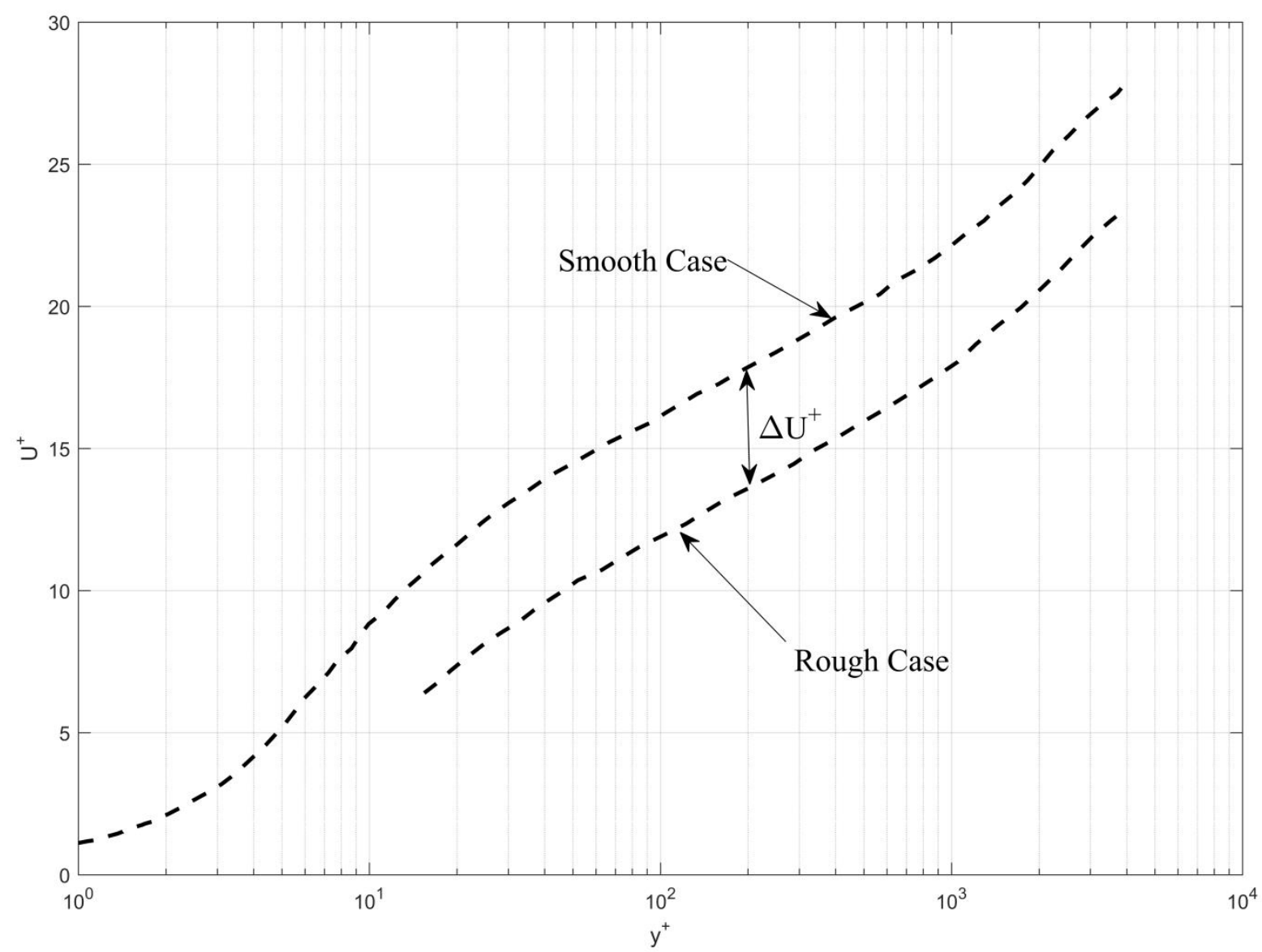

Figure 4 Illustration of a downward shift in log-law velocity profile due to roughness effect (redrawn Schultz and Swain 2000)

where $U^{+}$is the non-dimensional velocity in the boundary layer and $y^{+}$is the nondimensional normal distance from the wall. Details can be found in Schultz and Swain (2000) and (Hama, 1954). Once the roughness functions are determined i.e. $\Delta \mathrm{U}^{+}=f\left(\mathrm{k}^{+}\right)$for any test surfaces covered with specific roughness due to biofouling accumulation, the frictional drag of a ship or any object covered with this specified roughness can be found through similarity law analysis (Granville, 1958; Granville, 1987). When $\Delta C_{F}$ is calculated, it is employed in Eq.16 and percentage increases in the effective power are calculated.

\subsubsection{Fouling Ratings and Roughness Functions Correlation}

The roughness functions of any surfaces covered with the biofouling accumulation are required to calculate the increase in frictional resistance of the ship and need to be determined experimentally. However, conducting an experimental study with living organisms faces several challenges, for instance, protecting the surface with organisms while transferring it to a test facility as well as controlling differences in environmental conditions. In addition, any biologic substance leakage into the test facility may cause significant financial penalties.

As an alternative approach to experiments, the authors partially used the roughness functions data with the corresponding equivalent sand roughness heights provided by Schultz (2007). According to the data presented in Table 4, predicted fouling ratings were assessed in terms of condition descriptions and converted into equivalent sand roughness heights for slime, non-shell and heavy calcareous type fouling as shown in Table 5. 
Table 4 A ranges of representative coating and fouling conditions. The values of equivalent sand roughness heights and average coating roughness are based on the measurements of Schultz (2004) adapted from Schultz (2007)

\begin{tabular}{llll}
\hline Description of condition & NSTM Rating & $k_{S}(\mu m)$ & $R t_{50}(\mu m)$ \\
\hline Hydraulically smooth surface & 0 & 0 & 0 \\
Typical as applied AF coating & 0 & 30 & 150 \\
Deteriorated coating or light slime & $10-20$ & 100 & 300 \\
Heavy slime & 30 & 300 & 600 \\
Small calcareous fouling or weed & $40-60$ & 1000 & 1000 \\
Medium calcareous fouling & $70-80$ & 3000 & 3000 \\
Heavy calcareous fouling & $90-100$ & 10000 & 10000 \\
\hline
\end{tabular}

However, the roughness functions provided in Schultz (2007) are not suitable to represent the fouling conditions of $25 \%$ and $50 \%$ barnacle coverage. As indicated in Schultz (2004) and Schultz (2007) coverage areas of fouled plates for calcareous type fouling description were $60 \%$ for medium calcareous fouling and $75 \%$ for heavy calcareous fouling. For this reason, the authors used their own roughness functions for barnacle fouling proposed in Uzun et al. (2017).

The roughness functions of 20\% Mix configuration in Uzun et al. (2017) were used to represent 25\% coverage area whereas 50\% Mix configuration in Uzun et al. (2017) were used to represent $50 \%$ coverage for calcareous type fouling in this study. The fouling condition of which has more than $50 \%$ barnacle coverage area was represented by the roughness functions of heavy calcareous fouling provided by Schultz (2007). It is of note that, in our study, the fouling rating of 70 was taken in the $k_{s}$ range of 30-1000 if there is only an initial calcareous fouling accumulation up to 5\% coverage as similarly shown in Schultz (2007). Cases which have higher barnacle coverage, independently from FR, will be assessed as calcareous type fouling with coverage rating of 3, 4, and 5 according to the predicted SC area. Table 5 gives the surface descriptions and the corresponding characteristics used in this study.

Table 5 Fouling descriptions in relation with coverage ratings, percentage of coverage and equivalent sand roughness heights in conformity with roughness functions provided in Schultz (2007) and Uzun et al. (2017)

\begin{tabular}{|c|c|c|c|c|c|}
\hline & $\begin{array}{l}\text { Coverage } \\
\text { Rating }\end{array}$ & $\begin{array}{l}\text { Coverage } \\
\text { Area }\end{array}$ & $\begin{array}{l}\text { Fouling } \\
\text { Rating }\end{array}$ & $k_{s}(\mu m)$ & $\begin{array}{l}\text { Roughness } \\
\text { functions }\end{array}$ \\
\hline Hydraulically smooth surface & 0 & 0 & 0 & 0 & \\
\hline SPC type coating & 0 & 0 & 0 & 30 & Schultz (2007) \\
\hline Slime & $0-5$ & $0-100 \%$ & $0-20$ & $30-300$ & Schultz (2007) \\
\hline $\begin{array}{l}\text { Non-shell organisms } \\
\text { and very isolated barnacles } \\
\text { (up to } 5 \% \text { coverage) }\end{array}$ & $0-5$ & $0-100 \%$ & $0-70$ & $30-1000$ & Schultz (2007) \\
\hline Calcareous type fouling & 3 & $25 \%$ & - & 2000 & Uzun et al.(2017) \\
\hline Calcareous type fouling & 4 & $50 \%$ & - & 6000 & Uzun et al.(2017) \\
\hline Calcareous type fouling & 5 & $100 \%$ & - & 10000 & Schultz(2007) \\
\hline
\end{tabular}

Then, the roughness functions were employed in the model to be used in the Granville's (Granville, 1958; Granville, 1987) similarity law scaling procedure, similar to those performed in Demirel et al.,(2019) and Schultz (2007) for the length and the speed of the ship in question for each predicted equivalent sand roughness height. The predictions on $\Delta \mathrm{C}_{\mathrm{F}}$ were 
made under the assumptions that the listed fouling conditions can be simulated by the provided roughness functions and roughness length scales. The authors believe that it is a well-founded assumption as Schultz (2007) approved these assumptions and applicability of this method by comparing results of his predictions with the full-scale studies of Hundley and Tate Sr (1980) and Haslbeck and Bohlander (1992). The time-dependent equivalent sand roughness height, $k_{s}(\mathrm{t})$ can be calculated by Eq.17 and Eq.18. These equations are based on the parameters of $\mathrm{FR}_{\text {tot }}$ and $\mathrm{SC}_{\text {tot }}$ referring to total fouling rating in Eq.6 and the total percentage of SC area in Eq.8, respectively.

$$
\begin{gathered}
k_{s}(t)=\left\{\begin{aligned}
0.007143 F R_{t o t}{ }^{2}+13.36 F R_{t o t}+30, & 0<F R_{\text {tot }} \leq 70 \\
30, & F R_{\text {tot }}=0
\end{aligned}\right. \\
k_{s}(t)=\left\{\begin{aligned}
2.4669 S C_{t o t}{ }^{2}-24.84 S C_{t o t}+1065.7, & 5<S C_{t o t} \leq 50 \\
80 S C_{t o t}+2000, & 50<S C_{t o t} \leq 100
\end{aligned}\right.
\end{gathered}
$$

A regression as shown in Eq.17 was fitted to calculate the equivalent sand roughness heights for the predicted fouling ratings. The regression given in Eq.18 was used to predict the equivalent sand roughness heights when the model predicts the calcareous type fouling coverage is higher than 5\%. It is important to note that if the $\mathrm{SC}_{\text {tot }}$ is higher than $5 \% \mathrm{SC} \mathrm{k}_{\mathrm{s}}(\mathrm{t})$ is calculated using Eq.18. These regressions were developed based on the equivalent sand roughness heights provided in Table 5.

\section{VALIDATION}

\subsection{A Real ship Application}

Predictions of fouling ratings for the SC of calcareous type fouling and increases in frictional resistance were made for a 176-meter tanker coated with the same SPC type antifouling coating for a duration of the one-year operation. The time-dependent fouling ratings, the SC areas of calcareous type fouling and the increases in frictional resistance of the ship were predicted over the whole duration of the operation. The results were compared against the power data acquired by on-board measurement devices.

\subsubsection{Ship description and operation data}

The ship used in this case was a handy-max oil tanker. Table 6 shows the main features of the ship, which is mainly operated under short term contracts as reported in Coraddu et al. (2017). For this reason, the route of the ship is flexible and spread on the broad range of geographic locations all over the world. Therefore, it is an excellent case to validate the proposed model as the ship sails in the broader regions and spends considerable idle times at ports. The real-world dataset includes operational modes of manoeuvring, loading, unloading, sailing, and port stays. However, as the aim of this study is modelling biofouling growth during idle times during the one-year period, operational modes were divided into two groups as sailing (if the operation involves speed) and idle times (if there is no speed). 
Table 6 Ship profile

\begin{tabular}{ll}
\hline Ship type & Oil tanker \\
Design Length $(\mathrm{L})$ & $176 \mathrm{~m}$ \\
Design Draught $(\mathrm{T})$ & $11 \mathrm{~m}$ \\
Design Displacement $(\Delta)$ & $50800 \mathrm{t}$ \\
Design speed $(\mathrm{V})$ & 14 knots \\
\hline
\end{tabular}

Fig.5 shows the relative frequency of idle times according to the latitude degrees. It should be noted that the effect of longitude change on SST values was neglected as justified in Section 2.3.1. Idle time occurrence frequency was calculated through dividing the idle times at each latitude degree by the total idle times in the operation. It can be stated that the ship operation profile carries high fouling risk as the majority of idle times took place in the tropics and subtropics regions where latitude degrees remained between $0^{\circ}$ and $30^{\circ}$. Overall, the ship was idle approximately $30 \%$ of the entire operation in this region where SSTs are comparatively high.

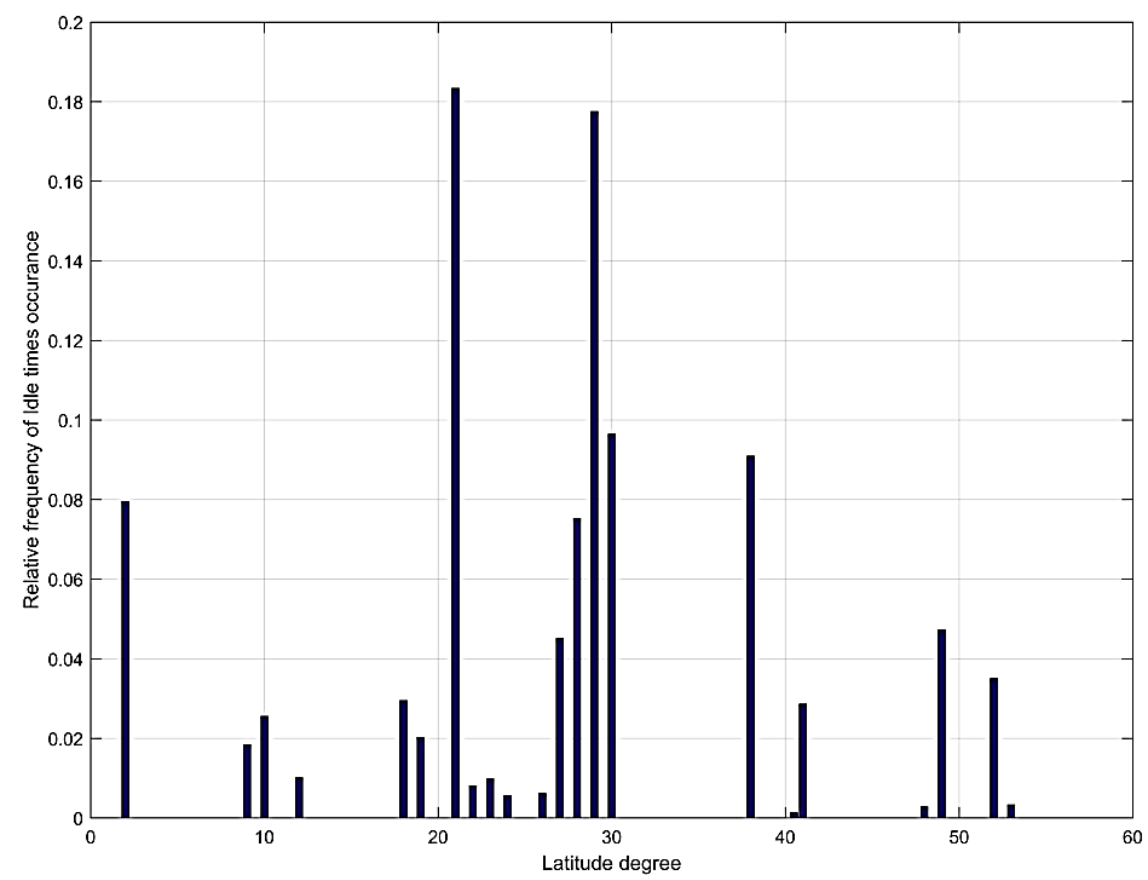

Figure 5 Relative frequency of idle time occurrence according to latitude

The ship is equipped with a data logging system for on-board monitoring and land-based performance control system. Although the data measuring frequency is $15 \mathrm{~s}$, it has been processed into $15 \mathrm{~min}$ averages in order to make it easier in terms of data handling. It is important to highlight that the company providing the data conducts the data processing, so the data were not influenced or modified by the authors. The list of available measurements and can be found in Table 7, while in Figure 6 the propulsive layout is depicted together with the propulsive measurements utilised for the validation part (Chapter 3.2).

As the on board devices make measurements in real-time, it is not easy to be sure of their reliability and accuracy during the monitoring. It is widely known that speed through water (LOG speed) measurement is partly reliable because the flow going through to the device can be affected by the hull or the other environmental conditions. Although the speed over 
ground (GPS speed) measurements are more consistent compared to LOG speed, it does not take into account current effects which can reach up to $2 \div 3$ knots and causes increases in ship power. A mass flowmeter is used to measure fuel consumptions since it is more accurate compared to volume flowmeters since there is no need to consider the uncertainty on fuel density. Although the fuel-specific energy content (LHV) was not measured uncertainty on LHV is around $\pm 2 \mathrm{MJ} / \mathrm{kg}$, which can cause a $\pm 5 \%$ variation in measurements. The shipyard informed that uncertainties of propeller speed, torque measurement and fuel mass flow are $\pm 0.1 \%, \pm 1 \%$ and $\pm 3 \%$ respectively. One year ship operation from $03 / 2012$ to $03 / 2013$ was taken as time domain for the time-dependent biofouling growth model.

Table 7 Measured values available from the continuous monitoring system (Coraddu et al., 2017)

\begin{tabular}{|c|c|c|c|c|c|}
\hline \# & Variable name & Unit & \# & Variable name & Unit \\
\hline$x_{1}$ & Time stamp & [YY-MM-DD, hh:mm] & $x_{20}$ & CPP Setpoint & {$[\%]$} \\
\hline$x_{2}$ & Latitude & {$\left[,{ }^{\circ},, "\right]$} & $x_{21}$ & CPP Feedback & [\%] \\
\hline$x_{3}$ & Longitude & {$[, ’, "]$,} & $x_{22}$ & Fuel Density & {$\left[\mathrm{kg} / \mathrm{m}^{3}\right]$} \\
\hline$x_{4}$ & Fuel consumption & {$[\mathrm{kg} / 15 \mathrm{mins}]$} & $x_{23}$ & Fuel Temperature & {$\left[{ }^{\circ} \mathrm{C}\right]$} \\
\hline$x_{5}$ & Auxiliary engines power & {$[\mathrm{kW}]$} & $x_{24}$ & Ambient Pressure & [mbar] \\
\hline$x_{6}$ & Shaft generator power & {$[\mathrm{kW}]$} & $x_{25}$ & Humidity & [\%] \\
\hline$x_{7}$ & Propeller shaft power & {$[\mathrm{kW}]$} & $x_{26}$ & Dew Point Temperature & {$\left[{ }^{\circ} \mathrm{C}\right]$} \\
\hline$x_{8}$ & Propeller speed & [rpm] & $x_{27}$ & Shaft Torque & {$[\mathrm{kN} \mathrm{m}]$} \\
\hline$x_{9}$ & Ship draft (forward) & {$[\mathrm{m}]$} & $x_{28}$ & Rudder Angle & {$\left[{ }^{\circ}\right]$} \\
\hline$x_{10}$ & Ship draft (aft) & [m] & $x_{29}$ & Acceleration $\mathrm{X}$ direction & {$\left[\mathrm{m} / \mathrm{s}^{2}\right]$} \\
\hline$x_{11}$ & Draft Port & [m] & $x_{30}$ & Acceleration Y direction & {$\left[\mathrm{m} / \mathrm{s}^{2}\right]$} \\
\hline$x_{12}$ & Draft Starboard & [m] & $x_{31}$ & Acceleration $\mathrm{Z}$ direction & {$\left[\mathrm{m} / \mathrm{s}^{2}\right]$} \\
\hline$x_{13}$ & Relative wind speed & {$[\mathrm{m} / \mathrm{s}]$} & $x_{32}$ & GyroX & {$[\mathrm{rpm}]$} \\
\hline$x_{14}$ & Relative wind direction & {$\left[{ }^{\circ}\right]$} & $x_{33}$ & GyroY & {$[\mathrm{rpm}]$} \\
\hline$x_{15}$ & GPS heading & {$\left[{ }^{\circ}\right]$} & $x_{34}$ & GyroZ & [rpm] \\
\hline$x_{16}$ & Speed over ground (GPS) & [kn] & $x_{35}$ & Roll & {$[\mathrm{rad}]$} \\
\hline$x_{17}$ & Speed through water (LOG) & [kn] & $x_{36}$ & Pitch & [rad] \\
\hline$x_{18}$ & Sea depth & [m] & $x_{37}$ & Yaw & [rad] \\
\hline$x_{19}$ & Seawater Temperature & {$\left[{ }^{\circ} \mathrm{C}\right]$} & & & \\
\hline
\end{tabular}

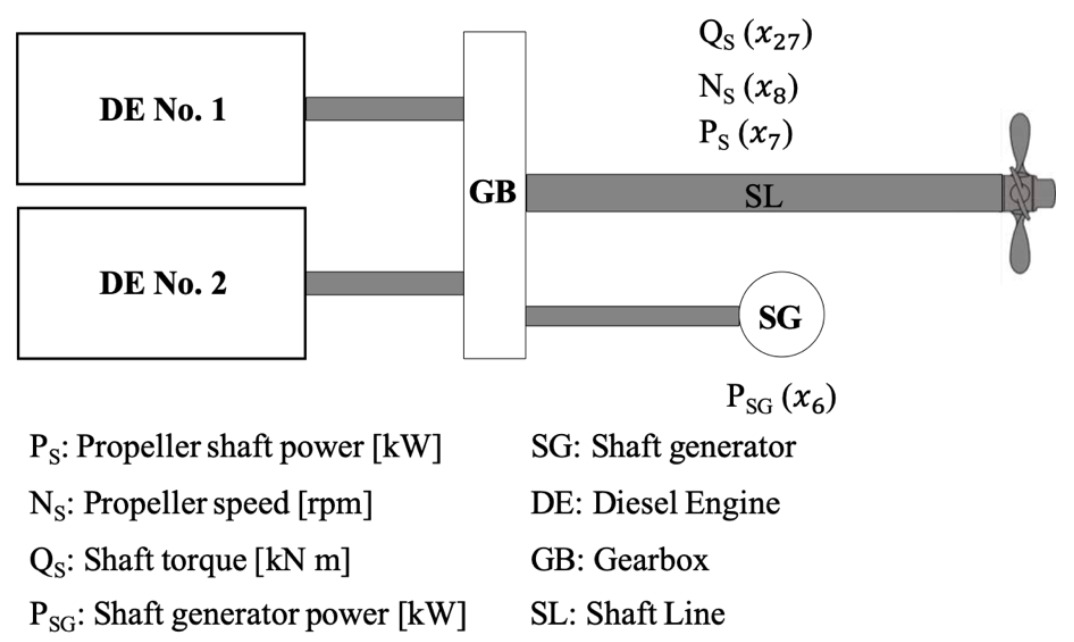

Figure 6 Propulsion plan layout 


\subsubsection{Time dependent predictions}

Fig.7 shows the estimated FR, percentage of calcareous type fouling surface coverage $(\% \mathrm{SC})$, and percentage increases in frictional resistance $\left(\% \Delta \mathrm{C}_{\mathrm{F}}\right)$ of the ship with respect to the time and absolute values of latitude degrees of the regions where the ship sailed or spent idle time. It can be seen from the figure that the fouling ratings were predicted to be $\sim 0.4$ for non-shell type fouling whereas this number altered to $\sim 6.3$ for slime type fouling and $\sim 6.7$ for total fouling rating at the end of one-year of operation. The percentage of the SC area for calcareous type fouling was predicted to be $\sim 4 \times 10^{-6}$ which means that the model predicted no calcareous type fouling. At the end of the one year of ship operation, the percentage increase in the frictional resistance due to biofouling was calculated to be $\sim 32 \%$ as shown in Fig.6. It is important to note that a significant percentage of increase in $\Delta \mathrm{C}_{\mathrm{F}}$ was observed in the month of Jan-13 from $\sim 5 \%$ to $\sim 30 \%$. This can be attributed to the fact that the ship spent $\sim 15$ days of idle time in a region of $\sim 0-1.5^{\circ}$ in latitude and $\sim 6$ days of idle time in a region of $\sim 10^{\circ}$ in latitude. These regions are equatorial which receives the most solar irradiance, therefore, these regions tend to have the highest SSTs as it can be predicted through Eq.5.
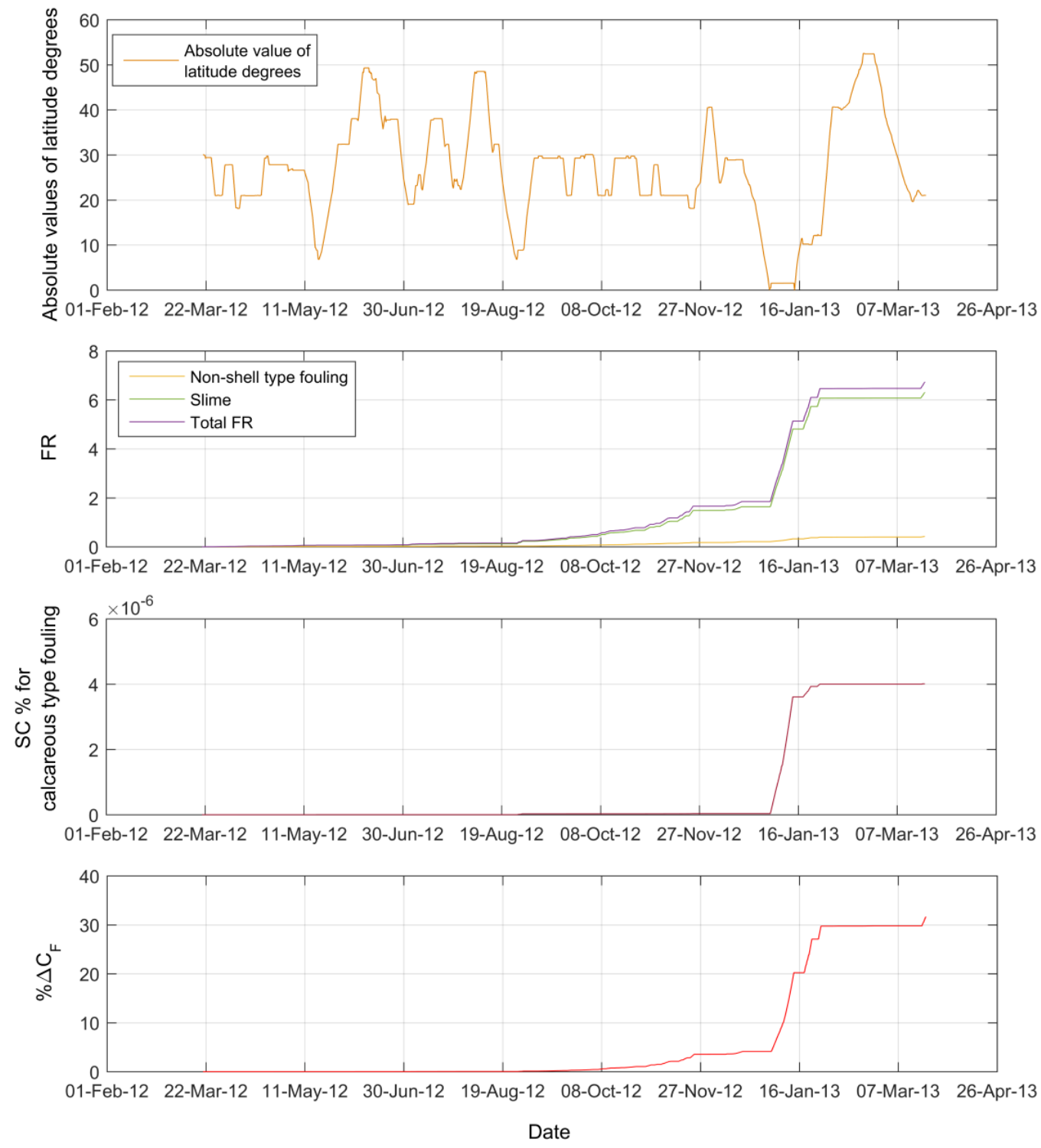

Figure 7 Estimation of the fouling ratings, percentage of surface coverage for calcareous type fouling, percentage of increases in the frictional resistance respect to time 


\subsection{Comparison of the results with power measurements}

The validation of the time-dependent biofouling model has been carried out by comparing the estimated delivered powers $\left(\mathrm{P}_{\mathrm{DE}}\right)$ to the delivered power $\left(\mathrm{P}_{\mathrm{DM}}-x_{17}\right)$ data acquired from real ship operation via on-board measuring devices.

In particular, a numerical model, has been developed to evaluate the ship estimated delivered powers, for different ship speed $\mathrm{V}\left(x_{17}\right)$, forward $\mathrm{T}_{\mathrm{f}}\left(x_{10}\right)$, and aft $\mathrm{T}_{\mathrm{a}}\left(x_{9}\right)$, drafts in calm water scenario. In this respect, the effects of manoeuvring, acceleration, and deceleration on ship power were eliminated along with the environmental effects such as waves, current and wind, by filtering. Table 8 summarises the filtered measurements and filtering conditions.

Table 8 Data filtering

\begin{tabular}{ll}
\hline Filtered Measurement & Filtering Condition \\
\hline Wind speed & $<3$ knots \\
Sea State & $<2$ Beaufort scales \\
Rudder position & $-1^{\circ}$ to $1^{\circ}$ \\
Speed through water rate of change & $\leq 0.25 \mathrm{knots} / \mathrm{min}$ \\
Mean Shaft speed rate of change & $\leq 0.5 \mathrm{rpm}$ \\
\hline
\end{tabular}

The model is based on the knowledge of the ship's hull geometry, mass distribution and the propeller characteristics. The system input taken into account, as reported in Figure 8, are the main propeller speed $\mathrm{N}\left(x_{8}\right)$, the ship speed $\mathrm{V}\left(x_{17}\right)$, and the forward $\mathrm{T}_{\mathrm{f}}\left(x_{10}\right)$, and aft $\mathrm{T}_{\mathrm{a}}\left(x_{9}\right)$, drafts. The estimated delivered powers, $\mathrm{P}_{\mathrm{DE}}$ is used as model output. The detailed description of the numerical model can be found in (Coraddu et al., 2017), nevertheless, for the sake of completeness, a summary is hereby reported.

The core of the procedure is the engine-propeller matching code utilised to evaluate the total delivered powers (Coraddu et al., 2011a) The prediction of ship resistance in calm water, and the evaluation of total hull resistance coefficient $\mathrm{C}_{\mathrm{T}}$ in Eq. 13 have been carried out utilising the Guldhammer Harvald (GH) method. For each forward and aft drafts (Figure 8) from the vessel historical dataset described in 3.1.1, the equilibrium displacement is calculated, together with the necessary input variables required by the GH method by means of the method proposed by in Coraddu et al. (2011b) It is worth noting that the propulsion coefficients $t$ and $w$ have been corrected in magnitude as reported in Lützen and Kristensen (2012):

$$
\begin{gathered}
w_{c}=w_{h}-0.45+0.08 \mathrm{M} \\
t_{c}=t_{h}-0.45+0.08 \mathrm{M}
\end{gathered}
$$

Where $w_{h}$ and $t_{h}$ are propulsion coefficients obtained with the $G H$ method, and $M$ is the length-displacement ratio.

The propeller thrust and torque have been computed for different pitch settings based on the knowledge of the geometrical features of the propeller, by means of a viscous method presented in Gaggero et al. (2010). The values were implemented in the numerical model through the non-dimensional thrust $\mathrm{K}_{\mathrm{T}}$ and torque $\mathrm{K}_{\mathrm{Q}}$ coefficients. Once the displacement, shaft rate of revolutions and vessel speed are selected, the equilibrium advance coefficient $\mathrm{J}_{\mathrm{eq}}$ is defined according to Eq. 21, together with the non-dimensional thrust and torque coefficient according to the Eqs 22 and 23: 


$$
\begin{gathered}
J_{e q}=\frac{V\left(1-w_{c}\right)}{n D} \\
K_{Q}=\frac{Q}{\rho n^{2} D^{5}} \\
K_{T}=\frac{T}{\rho n^{2} D^{5}}
\end{gathered}
$$

where $\mathrm{w}_{\mathrm{c}}$ is the wake factor corrected in magnitude, $\mathrm{n}$ is the propeller rate of revolution, $\mathrm{D}$ is the propeller diameter and $\mathrm{T}$ is the required thrust of the propeller. Finally the open water propeller efficiency $\eta_{o}$ can be estimated utilising Eq 24:

$$
\eta_{o}=\frac{J_{e q}}{2 \pi} \frac{K_{T}}{K_{Q}}
$$

The propeller open water torque, $\mathrm{P}_{\mathrm{o}}$ can be evaluated according to Eq. 25

$$
P_{o}=2 \pi n Q_{o}=2 \pi n K_{Q} \rho n^{2} D^{5}
$$

Starting from the propeller torque, the estimated delivered power, $\mathrm{P}_{\mathrm{DE}}$ is computed by the taking into account the different components of the total propulsion efficiencies as given in Eq.26.

$$
P_{D E}=\frac{P_{E}}{\eta_{T}}=\frac{P_{E}}{\eta_{o} \eta_{h} \eta_{r} \eta_{s}}
$$

Here $\eta_{\mathrm{t}}$ is the overall efficiency, while $\eta_{\mathrm{h}}$ is the hull efficiency, $\eta_{\mathrm{o}}$, is the propeller efficiency in open water, $\eta_{\mathrm{r}}$ is the relative rotative efficiency and $\eta_{\mathrm{s}}$ is the shaft line efficiency. The hull efficiency $\eta_{h}$ is a function of the modified wake fraction, $w_{c}$, and the modified thrust deduction fraction, $t_{c}$.

Vessel

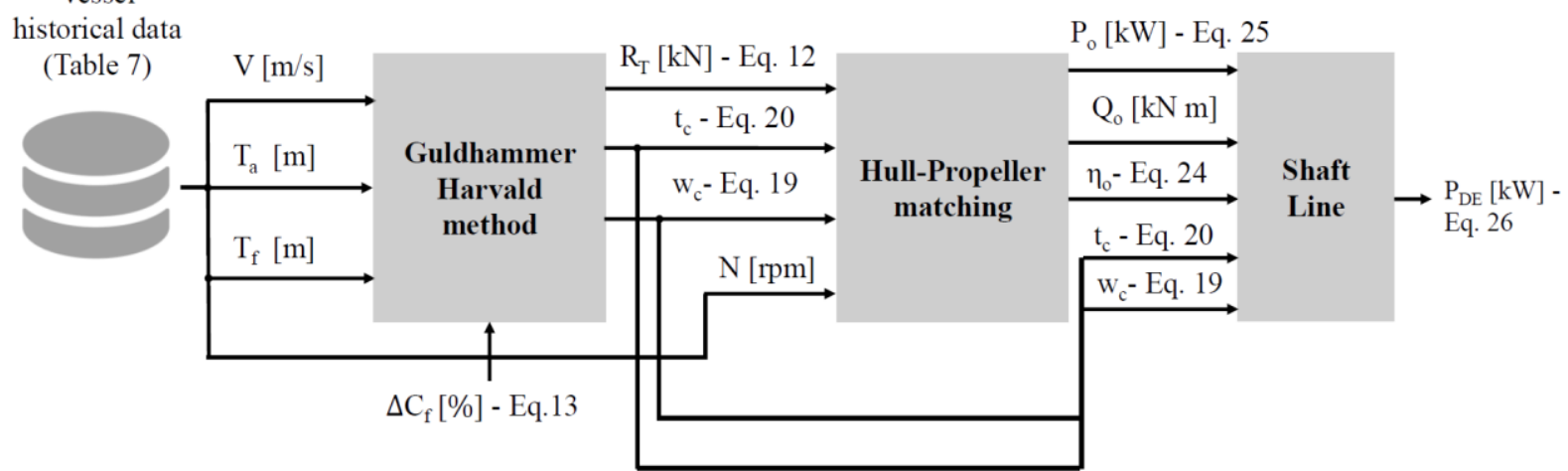

Figure 8 Estimated delivered power - modelling flowchart

The validation of the time-dependent biofouling was carried out through three case analyses, namely Case A, Case B and Case $\mathrm{C}$ on delivered power comparisons in two separate time periods, as shown in Fig 9 and Table 9. Fig 10 and Fig 11 shows $P_{D M}$ values at varying ship speeds in the first and second period.

It is of note that the Case A was carried out in the first time period in which the ship was considered fouling-free whereas Case B and Case C were conducted in the second time period in which the ship has fouling. The analyses were performed for the ship in the calm 
water scenario in which ship speed range from 10 knots to 15 knots whereas ship displacements range from 50000 to 52000 tons.

Independently of the adopted scenario, the authors define the error that the proposed approach commits on approximating the real data with reference to the Relative Error Percentage (REP) indexes of performance. The REP is computed by taking the mean square loss but a normalization term composed of the sum of the squared true values. Then the result is square rooted and reported in percentage:

$$
R E P=100 \sqrt{\sum_{i=1}^{n} \frac{\left(P_{D E_{i}}-P_{D M}\right)^{2}}{\sum_{i=1}^{n} P_{D M}^{2}}}
$$

Table 9 Time periods for delivered power comparison

\begin{tabular}{|c|c|c|c|c|c|c|}
\hline Case & Periods & Dates & Samples & $\begin{array}{c}\text { Fouling } \\
\text { Status }\end{array}$ & $\begin{array}{c}\text { Speed Range } \\
{[\mathrm{knot}]}\end{array}$ & $\begin{array}{c}\text { Displacement } \\
\text { Range [t] }\end{array}$ \\
\hline $\mathrm{A}$ & $1 \mathrm{st}$ & $\begin{array}{c}\mathrm{t}_{01:}: 17 / 05 / 12 \\
\mathrm{t}_{\mathrm{E} 1}: 24 / 05 / 12\end{array}$ & 76 & 0 & $12-13.5$ & \multirow{2}{*}{$50000-52000$} \\
\cline { 1 - 3 } $\mathrm{B}$ & 2nd & $\begin{array}{c}\mathrm{t}_{02}: 22 / 02 / 13 \\
\mathrm{t}_{\mathrm{E} 2}: 18 / 03 / 13\end{array}$ & 98 & 0 & \multirow{2}{*}{$10.5-13.5$} & \\
\cline { 1 - 1 } $\mathrm{C}$ & & & 1 & & \\
\hline
\end{tabular}

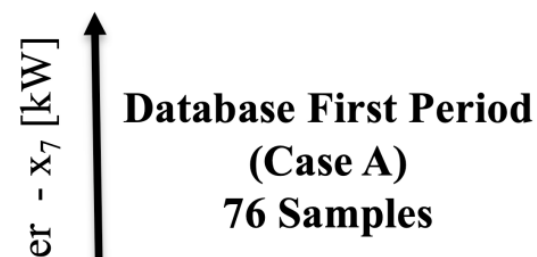

Database Second Period

(Case B, C)

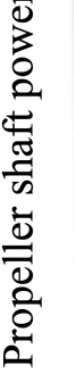

76 Samples

98 Samples
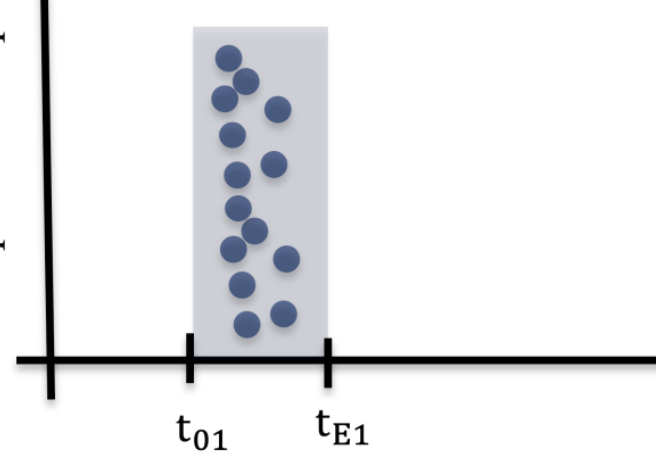

$17 / 05 / 2012$

$24 / 05 / 2012$

$22 / 02 / 2013$

time

Figure 9 Time periods for delivered power comparison 


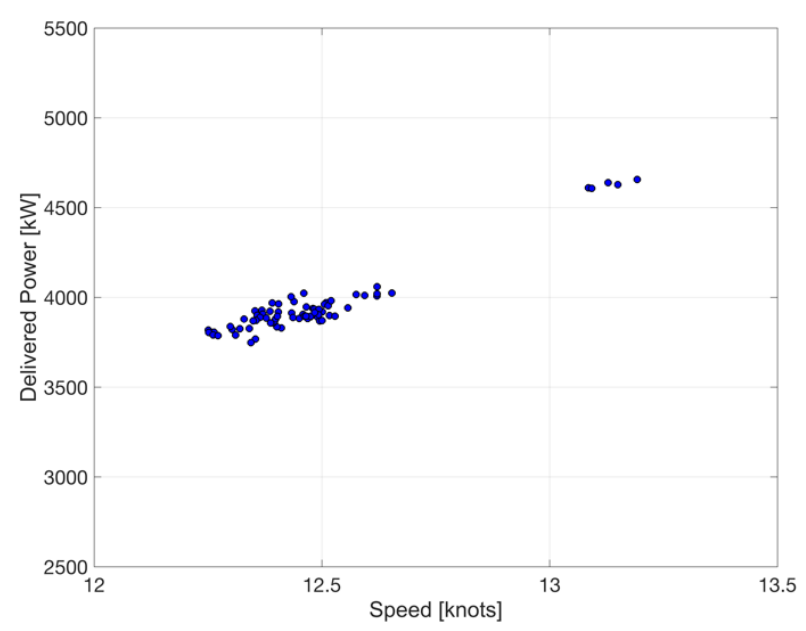

Figure 10 First Period - 17/05/12-24/05/12

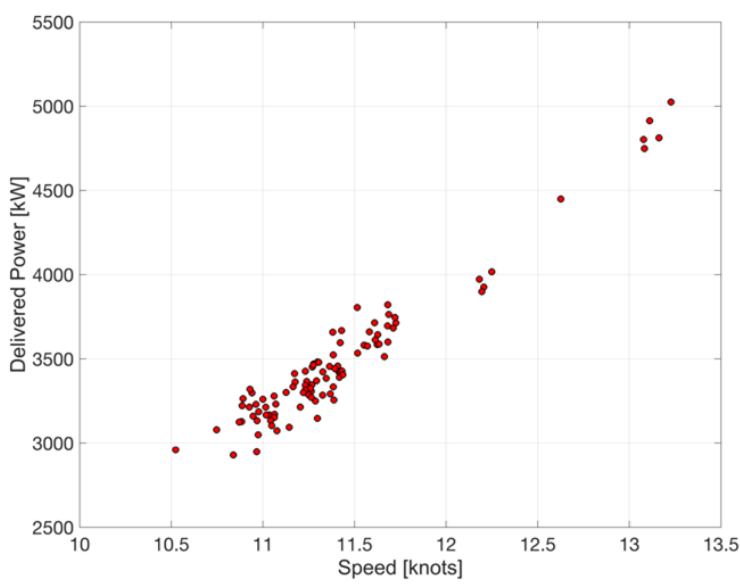

Figure 11 Second Period - 22/02/13$26 / 03 / 13$

\section{(a) CASE A}

Fig. 12 shows the PDM and PDE values at varying ship speeds, while Fig.13 shows the scatterplots between predicted and real values of the output values.

Fig. 14 reports the relative frequencies of the REP distribution between the $\mathrm{P}_{\mathrm{DM}}$ and $\mathrm{P}_{\mathrm{DE}}$ values. The comparisons, in this case, were made to ensure that the in-house GH code accurately predicts delivered power values where the ship hull is considered as smooth after approximately two months from the beginning in the first time period (without any fouling). The analysis shown in Fig. 12, 13 and 14 revealed that the $P_{D E}$ values matched reasonably well with $\mathrm{P}_{\mathrm{DM}}$ such that the average REP value was only $1.8 \%$. These results have further strengthened the confidence in the hypothesis that the GH power prediction method is a credible way to make these analyses for the fouled condition.

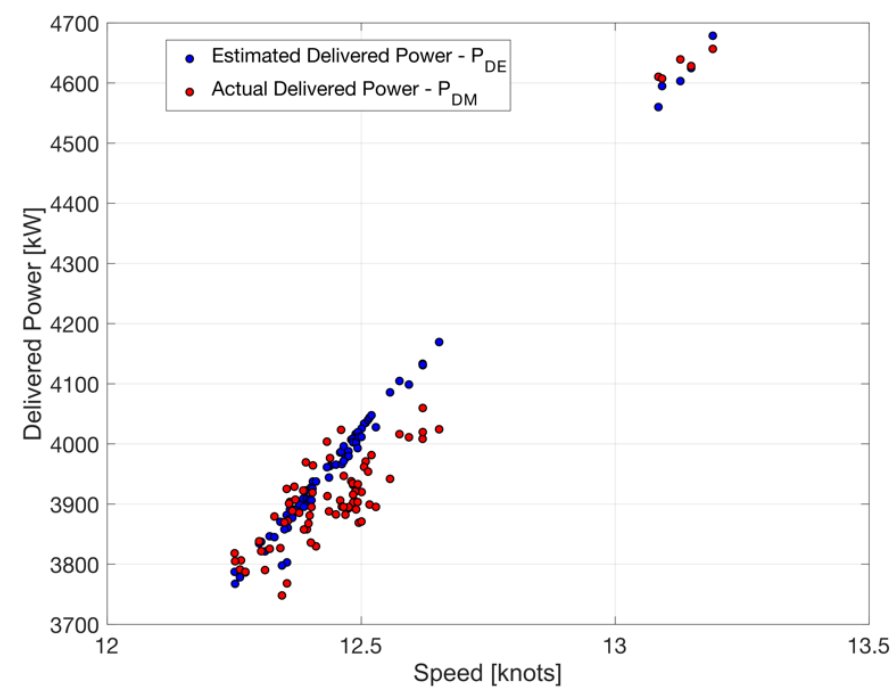

Figure $12 \mathrm{P}_{\mathrm{DM}}$ and $\mathrm{P}_{\mathrm{DE}}$ comparisons at various ship speeds - CASE A 


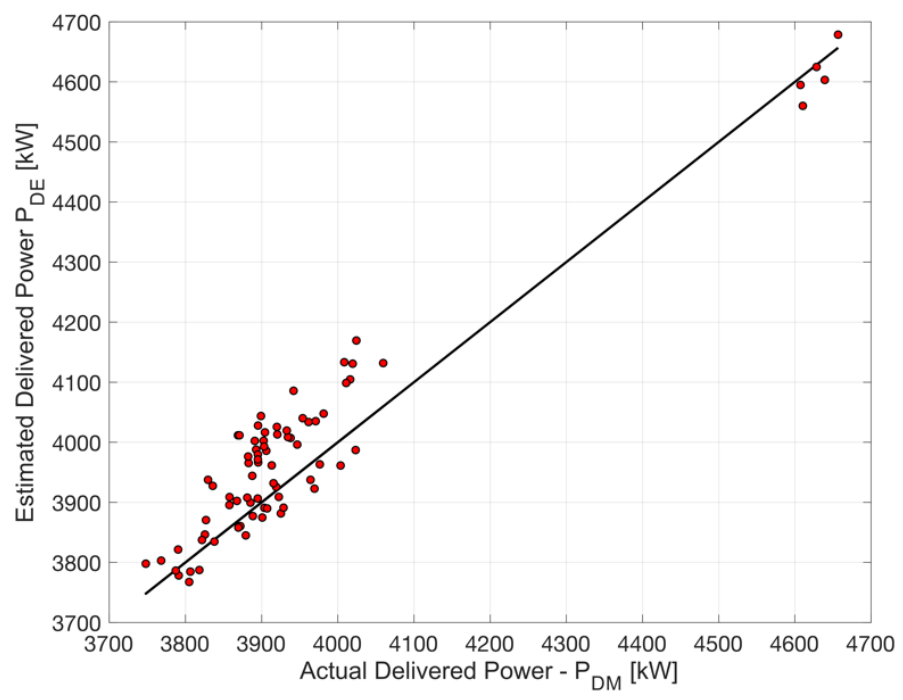

Figure 13 GH model scatterplot - CASE A

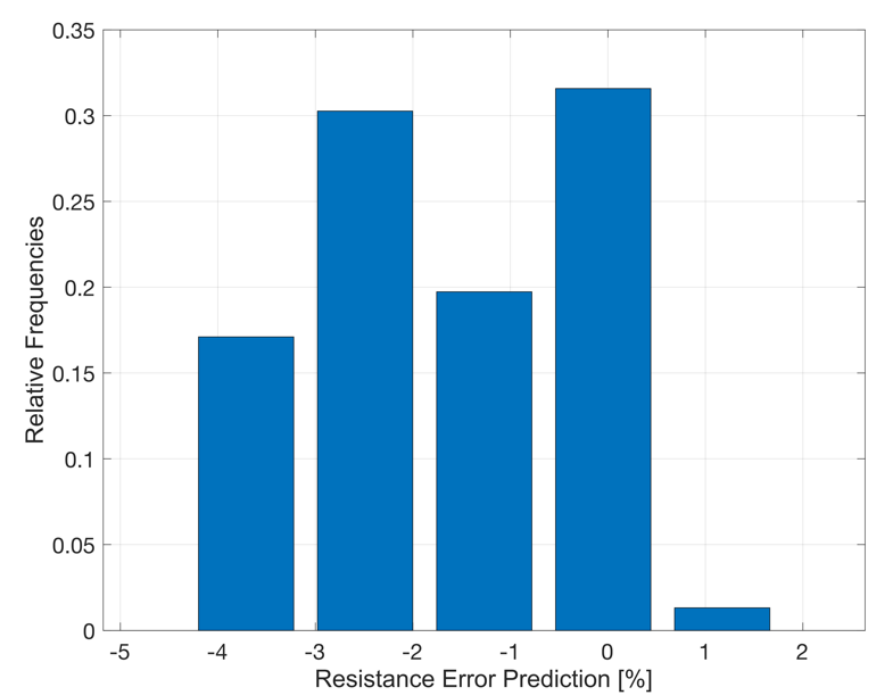

Figure 14 Relative frequencies of relative error percentage distribution - CASE A

\section{(b) CASE B (No fouling correction)}

Fig. 15 shows the $\mathrm{P}_{\mathrm{DM}}$ and $\mathrm{P}_{\mathrm{DE}}$ values at varying ship speeds, while Fig.16 shows the scatterplots between predicted and real values of the output values. Fig. 17 reports the relative frequencies of the REP distribution between the $\mathrm{P}_{\mathrm{DM}}$ and $\mathrm{P}_{\mathrm{DE}}$. The effective power estimation was made using the GH power prediction method similar to that used for the CASE A, i.e. without taking into account any fouling effect. The analysis, in this case, was performed to show the effect of biofouling on ship resistance and powering after a one-year operation in the second time period. Due to fouling accumulation, it is expected to observe significant difference between the $\mathrm{P}_{\mathrm{DE}}$ and $\mathrm{P}_{\mathrm{DM}}$ values. This difference was reflected in REPs between $\mathrm{P}_{\mathrm{DE}}$ and $\mathrm{P}_{\mathrm{DM}}$. The results presented in Fig.15 and Fig.16 indicate that there is a significant discrepancy between $\mathrm{P}_{\mathrm{DE}}$ and $\mathrm{P}_{\mathrm{DM}}$ values due to biofouling accumulation on the ship hull. Fig. 17 presents relative frequencies of REP values distribution between $\mathrm{P}_{\mathrm{DE}}$ and $\mathrm{P}_{\mathrm{DM}}$. The average REP value was calculated to be $\sim 14.7 \%$. 


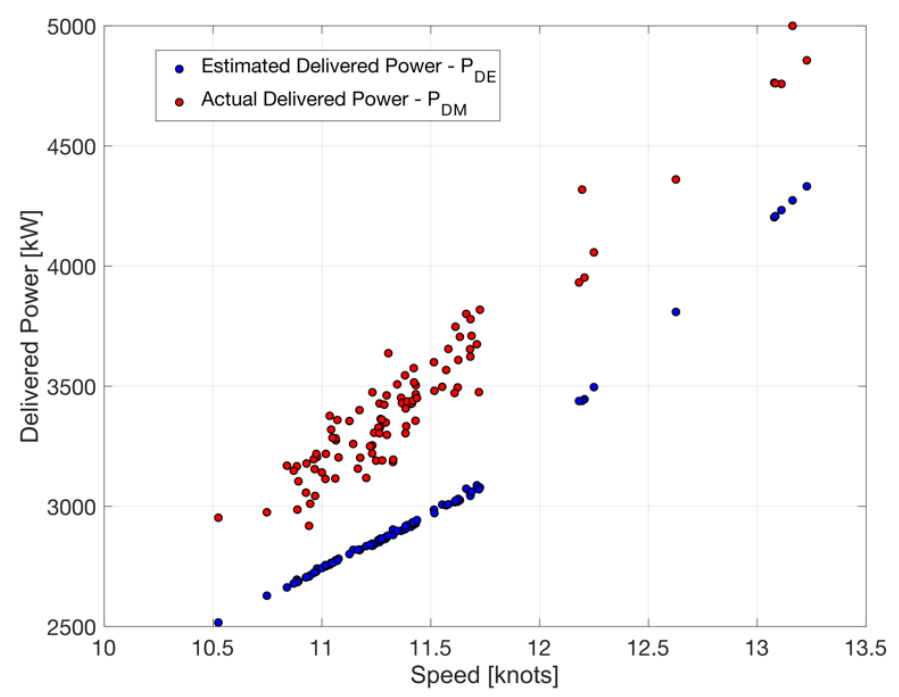

Figure $15 \mathrm{P}_{\mathrm{DM}}$ and $\mathrm{P}_{\mathrm{DE}}$ comparisons at various ship speeds - CASE B

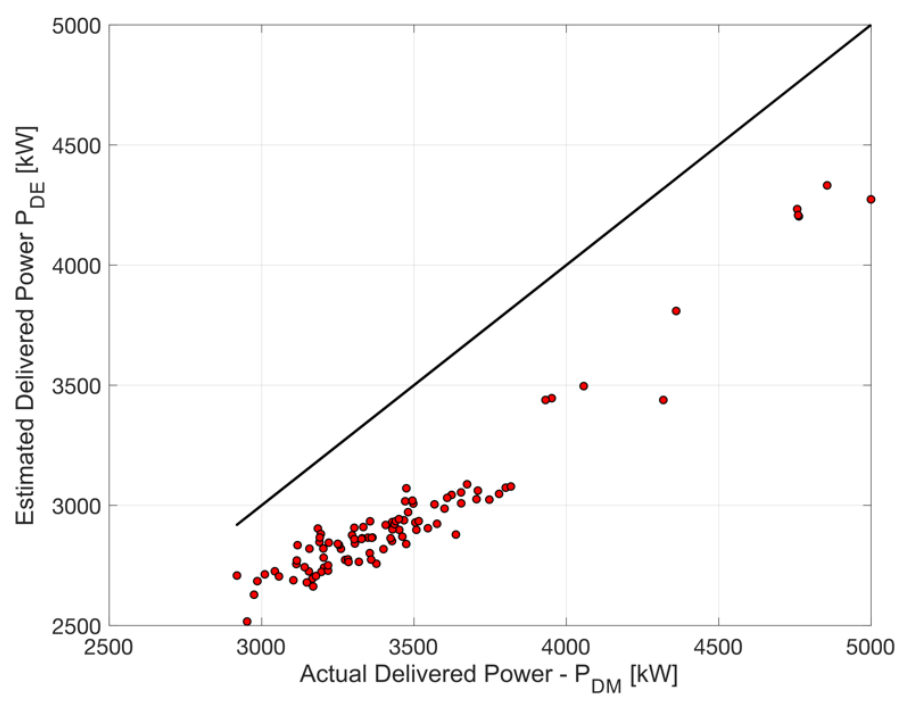

Figure 16 GH model scatterplot - CASE B

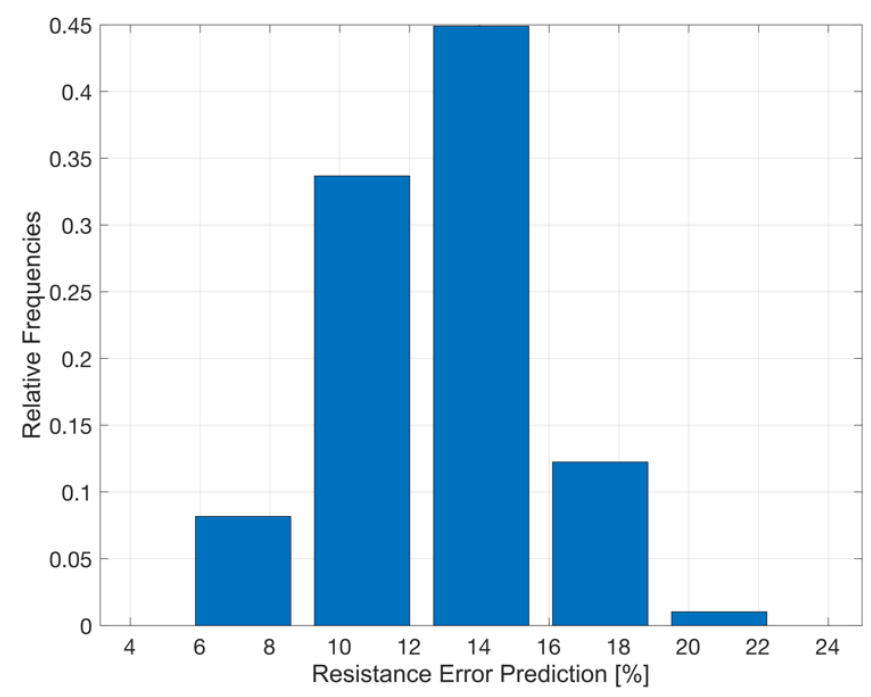

Figure 17 Relative frequencies of relative error percentage distribution - CASE B 


\section{(c) CASE C (fouling correction)}

The $\Delta \mathrm{C}_{\mathrm{F}}$ predictions were employed into the equation of $\mathrm{C}_{\mathrm{T}}$, as shown in Eq. 13, and Fig. 8 , in the $\mathrm{GH}$ power prediction code. Following this, the analysis was repeated to test the timedependent model's predictions in the second time period.

Shown for the comparisons in Fig. 18 is the actual delivered power measured by on-board devices together with the estimated delivered power $\left(\mathrm{P}_{\mathrm{DE}}\right)$ predicted by $\mathrm{GH}$ code employed with $\Delta \mathrm{C}_{\mathrm{F}}$ predictions. From Fig. 19 , it is evident that once the $\Delta \mathrm{C}_{\mathrm{F}}$ predictions were employed into $\mathrm{GH}$ code, $\mathrm{P}_{\mathrm{DE}}$ values showed a good correlation with $\mathrm{P}_{\mathrm{DM}}$ values with an only 2.7\% REP value. In addition, Fig. 20 illustrates the relative frequencies of relative error percentage distribution.

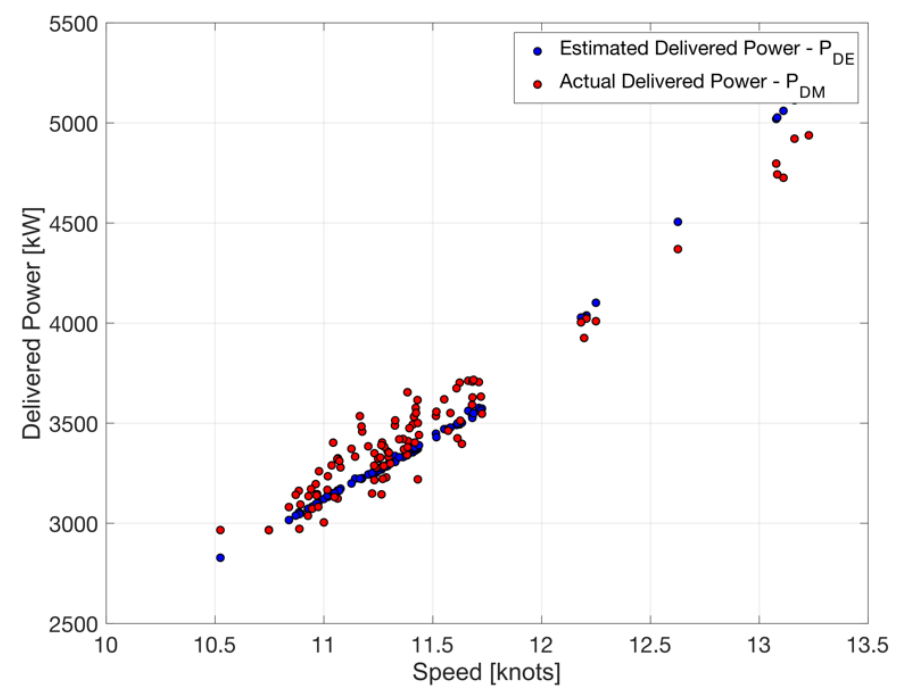

Figure $18 \mathrm{P}_{\mathrm{DM}}$ and $\mathrm{P}_{\mathrm{DE}}$ comparisons at various ship speeds - CASE C

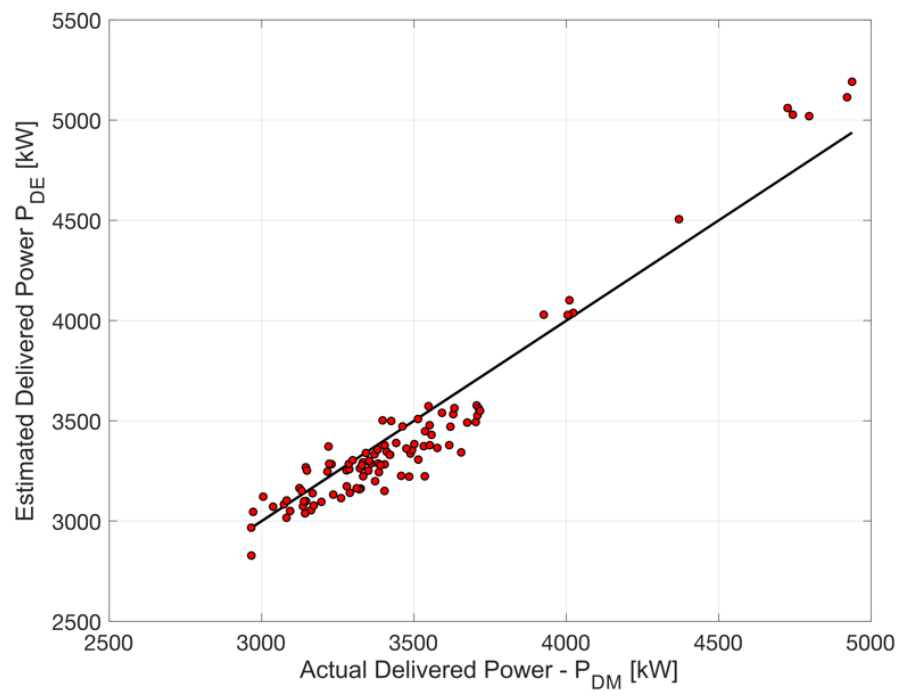

Figure 19 GH model scatterplot - CASE C 


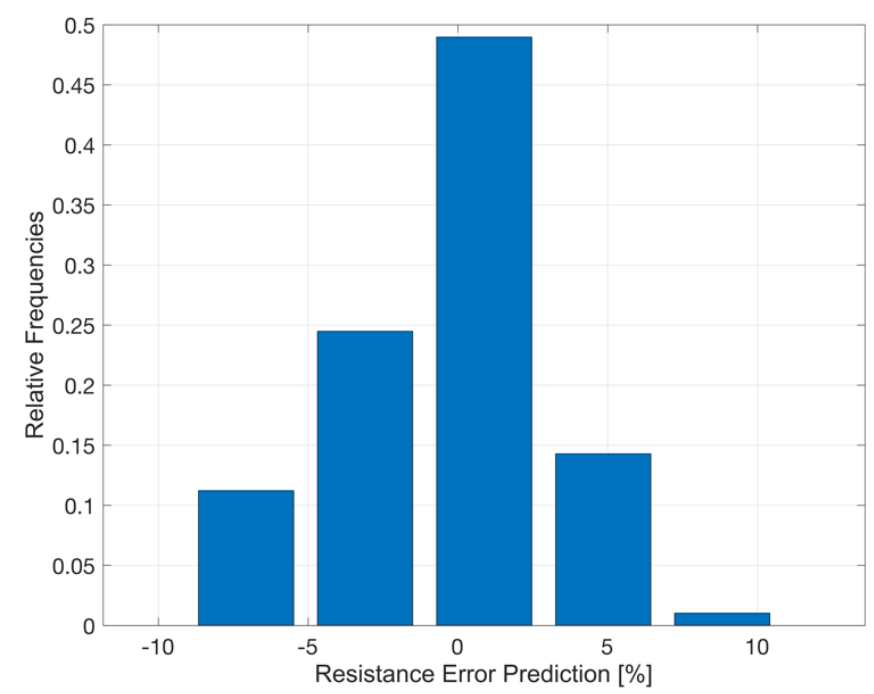

Figure 20 Relative frequencies of relative error percentage distribution - CASE C

Table 10 Summary of case results

\begin{tabular}{lll}
\hline CASE & No of Sample & REP [\%] \\
\hline A & 76 & 1.8 \\
B & 98 & 14.7 \\
C & 98 & 2.7 \\
\hline
\end{tabular}

Table 10 shows the results of the analysis conducted in each case through REP values of a given number of samples. From the Table 10, it is evident that average REP values between $\mathrm{P}_{\mathrm{DM}}$ and $\mathrm{P}_{\mathrm{DE}}$ were calculated to be $\sim 1.8$ over a 76 of sample for Case $\mathrm{A}$ whereas this value changed to $\sim 14.7$ and $\sim 2.7$ over 98 of sample for Case B and Case C, respectively.

The results presented in Table 10 summarise that the GH power prediction code predicted the delivered power accurately with an only $\sim 1.8 \%$ REP in Case A in which ship had no fouling on the hull surface. However, after one year it was observed that comparison between the $\mathrm{P}_{\mathrm{DM}}$ and $\mathrm{P}_{\mathrm{DE}}$ in Case $\mathrm{B}$ average REP value increased to $\sim 14.7 \%$ due to the effect of biofouling on the ship hull. Finally, the time-dependent biofouling model's predictions were tested through employing the predicted $\Delta \mathrm{C}_{\mathrm{F}}$ into $\mathrm{GH}$ power prediction code. The results show that average REP values decreased from $\sim 14.7$ to $\sim 2.7 \%$ in Case $\mathrm{C}$ once the predictions of time-dependent biofouling model are taken into account.

The result of the analyses showed that there is a very good agreement between the model's prediction and the real data. This can be accepted as a strong indication for the validation of the model for this case. The authors believe that further validation is needed for longer ship operation periods and different ships. For this reason, a case study was carried out to test the model for a different ship type operating for a longer period. 


\section{CASE STUDY}

A case study was conducted for a 258 m crude oil carrier coated with the same SPC type antifouling coating for the duration of a $\sim 3$-year operation. The model predicted fouling ratings, calcareous type fouling coverage area, percentage increases in frictional resistance of ship and percentage increase of the effective power over the 3 years of ship operation. The predicted percentage increases in effective power were compared with the results provided by a company which gives performance monitoring service for ships based on the data recorded by the crew or auto log systems in ships at periodic intervals. The recorded data then are corrected for wind, waves, sea current, fuel oil quality, and water temperature in order to calculate the effect of biofouling on ship resistance and powering at calm water scenario. The report provided by the shipping company indicated that the percentage increase in effective power due to biofouling for the ship in the selected time period was calculated to be $\sim 21 \%$ at the design speed of 15 knots.

\subsection{Ship description and Operation data}

The ship profile was presented in Table 11. The ship route representing the regions where the ship sailed during the selected time period was illustrated in Fig. 21. It is evident from Fig.21 and 22 the ship was mostly operated in the Atlantic Ocean and had a substantial percentage of idle times in a region between the latitude degrees of $0^{\circ}$ to $10^{\circ}$ (loading operation) and $30^{\circ}$ to $50^{\circ}$ (unloading operation). The total idle time for the $\sim 3$ years of ship operation was reported to be $\sim 322$ days.

Table 9 Ship profile

\begin{tabular}{ll}
\hline Ship type & Crude oil carrier \\
Design Length & $258 \mathrm{~m}$ \\
Design Breadth (B) & $45.5 \mathrm{~m}$ \\
Design Draught (T) & $16 \mathrm{~m}$ \\
Design Displacement $(\Delta)$ & $160000 \mathrm{t}$ \\
Design speed $(\mathrm{V})$ & 15 knots \\
\hline
\end{tabular}




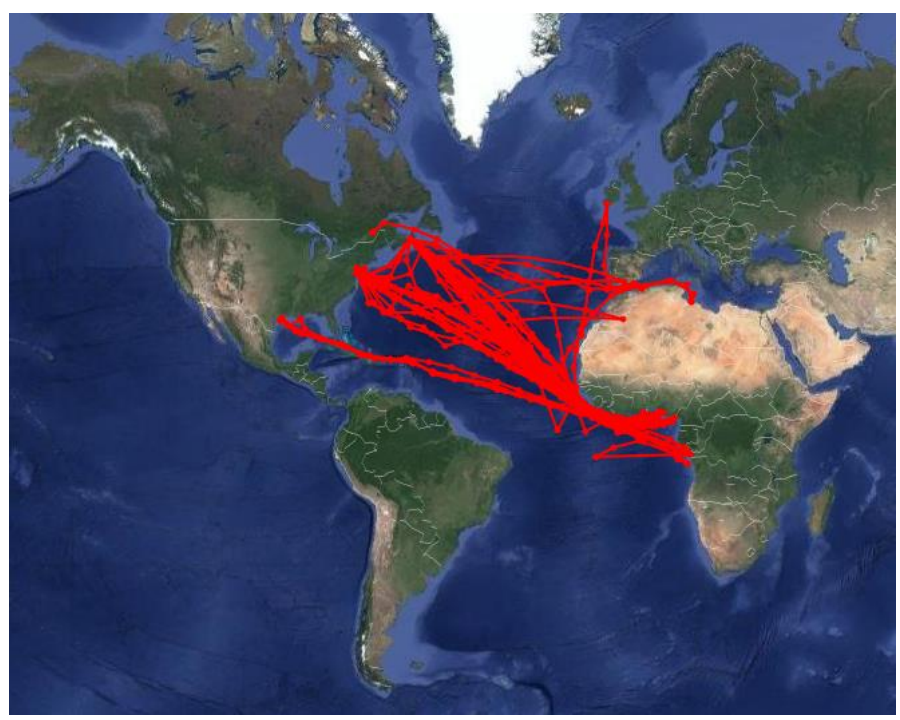

Figure 21 Illustration of the ship routes.

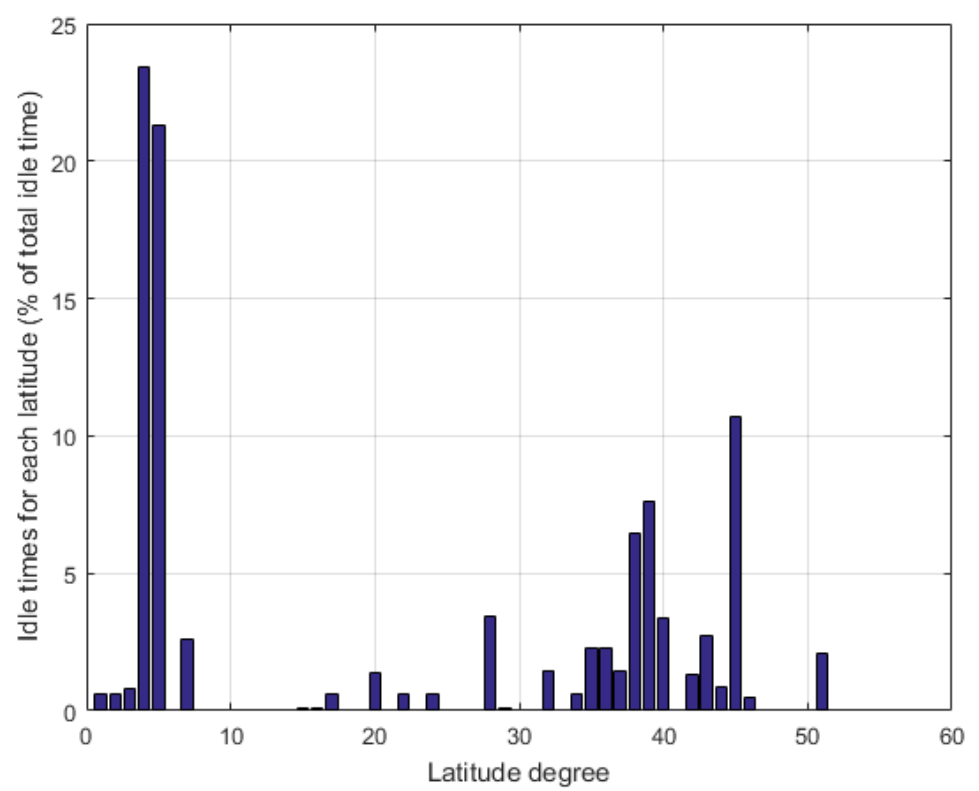

Figure 22 Idle times for each latitude degree (\% of total idle time)

\subsection{Results}

Fig. 23 demonstrates the estimated fouling ratings (FR), calcareous type fouling surface coverage $(\mathrm{SC} \%)$ and percentage increases in frictional resistance $\left(\% \Delta \mathrm{C}_{\mathrm{F}}\right)$ and effective power $(\triangle \mathrm{PE} \%)$ of the ship with respect to the time.

The results presented in Fig. 23 show that fouling ratings for the case study were predicted to be $\sim 30$ and $\sim 20$ for non-shell and slime type fouling respectively, whereas total fouling rating was predicted to be $\sim 50$. Percentage of SC for calcareous type fouling was predicted to be $2 \times 10^{-3}$, which means no calcareous type fouling was estimated for this case.

The change in the frictional resistance of the ship during the 3 years of operation was illustrated depending on the predicted fouling ratings and SC areas for calcareous type fouling, as shown in Fig. 23. As seen from the figure, the percentage increase in the frictional 
resistance was predicted to be $\sim 43 \%$ which in return caused $\sim 25 \%$ increases in the effective power of the ship at the design speed of 15 knots at the end of 3 years operation.

It is evident from Fig. 23 that the $\Delta \mathrm{P}_{\mathrm{E}} \%$ predicted by the time-dependent model, illustrated with blue line, and the $\Delta \mathrm{P}_{\mathrm{E}} \%$ provided by ship performance analyst company, illustrated by the orange line, showed different trends. This can be attributed to the fact that the values provided by the company are average values for a selected time of period; therefore, the increase follows a linear trend as shown in Fig.23. However, it is expected that the accumulation of biofouling on ship hull takes time dependency on the efficiency of fouling control coatings in real conditions.

The $\Delta \mathrm{P}_{\mathrm{E}} \%$ predicted by the time-dependent model was also averaged over the operation time to present a better comparison with the $\Delta \mathrm{P}_{\mathrm{E}} \%$ given by the company. It was observed that there is only $\sim 4 \%$ difference between the results. 

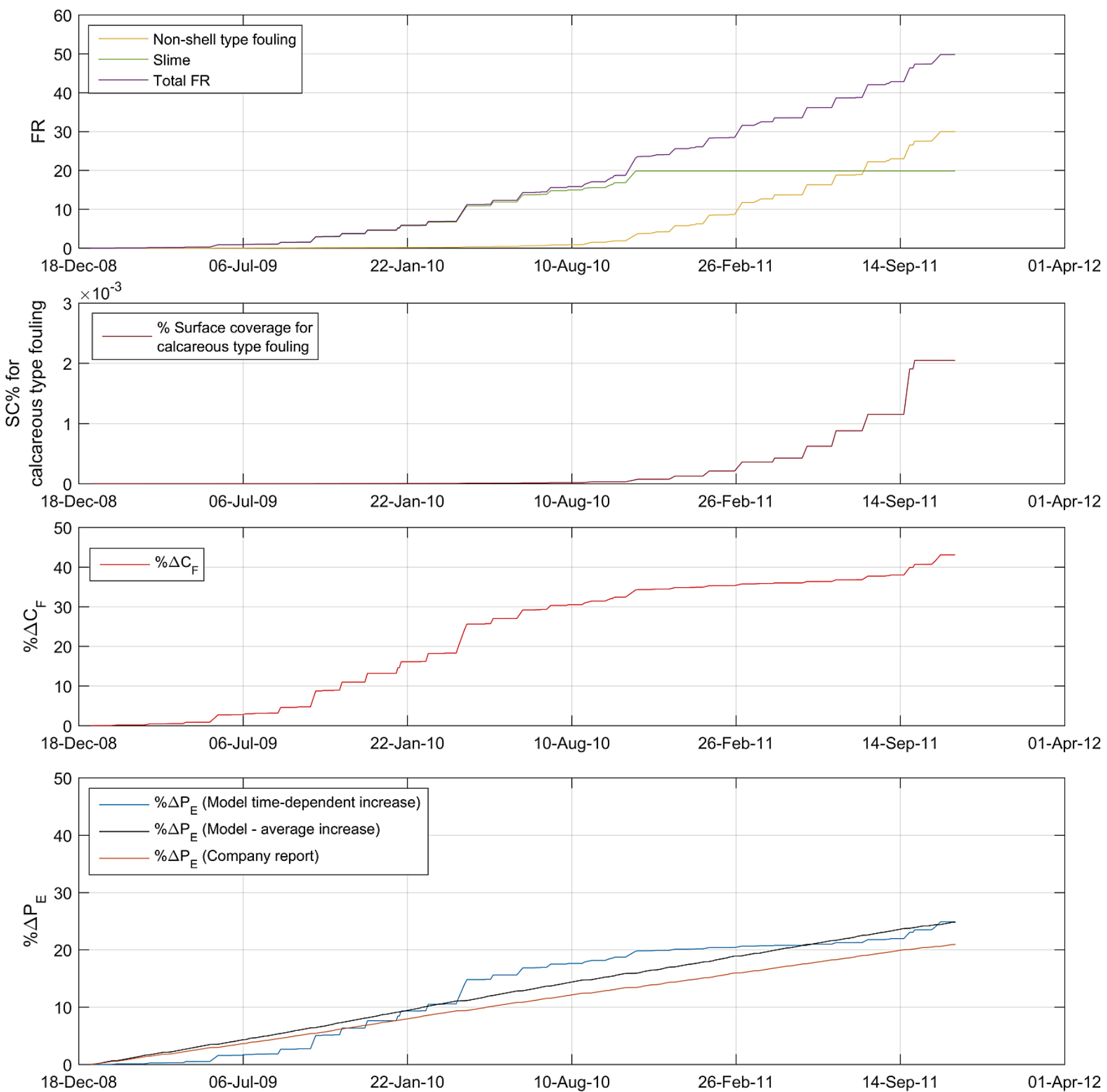

Figure 23 Estimation of the fouling ratings, percentage of surface coverage for calcareous type fouling, increase in the frictional resistance and percentage increase in effective power with respect to time 


\section{DISCUSSION AND CONCLUSION}

A novel model which correlates the antifouling coating field tests and ship operations was developed to predict time-dependent biofouling growth for the ship operation in question. The effects of time-dependent biofouling growth on ship frictional resistance and powering were predicted using the developed model.

The antifouling field tests data, which were provided by a paint company for an SPC type coating was used to create a time and fouling growth correlation at two separate locations where the coating was tested for around three years. It was observed that a Gaussian type fit sufficiently represented the time and fouling growth correlation. First, the coating performance coefficients, which show the trend of biofouling growth against time, were determined by using Gaussian fit at the test locations and then these coefficients were derived for any region in question using the sea surface temperature as an extrapolation/interpolation parameter. However, the fouling rating function, which was provided by the paint company, was not suitable to predict the effect of the SC area of calcareous type fouling. Therefore, a sub-logistic growth model was also developed for estimating the SC area of calcareous type fouling. It is important to note that idle times during the ship operation was employed as the time parameter in the developed model, which means the model predicts biofouling growth over the periods when the ship is stationary.

Predicted fouling ratings and the SCs for calcareous type fouling were then, turned into $k_{s}$ values based on the data provided in the literature (Schultz, 2007) (Uzun et al., 2017). The $k_{s}$ values and corresponding roughness functions for the predicted fouling condition were employed in Granville's similarity law procedure (Granville, 1958) to predict the effect of biofouling on frictional resistance and powering at ship scale.

Firstly, the predictions were made using one-year long ship operation data, which is acquired by on-board measuring devices. The fouling ratings, calcareous type fouling coverages along with the percentage increase in ship frictional resistance and effective power were predicted for calm water conditions. The model was validated by comparing the data obtained by onboard devices and filtered by only retaining those data recorded in calm water conditions and the predicted power values via the $\mathrm{GH}$ method in two periods, in the beginning, and at the end of one-year of operation. The GH power prediction method (Guldhammer and Harvald, 1974) was used to predict delivered power at calm water scenarios. It was shown that the $\mathrm{P}_{\mathrm{DE}}$ values showed a good agreement with the $\mathrm{P}_{\mathrm{DM}}$ values, with an average error of $\sim 1.79 \%$ in REP in the first period when the ship was clean. On the other hand, it was observed that comparisons between $\mathrm{P}_{\mathrm{DE}}$ and $\mathrm{P}_{\mathrm{DM}}$ in the second period showed a considerable change in REP values with a $\sim 14.73 \%$ difference. This can be attributed to the fact that during a one-year of ship operation biofouling occurred on the ship hull and caused an increase in ship resistance and powering. Following that, the $\Delta \mathrm{C}_{\mathrm{F}}$ values predicted using time-dependent biofouling growth model was included in the GH power prediction code. Then, it was observed that REP values significantly reduced to $\sim 2.68 \%$.

Following that, a case study was performed on a 3-year of ship operation. The timedependent biofouling growth prediction was made and increases in $\Delta \mathrm{C}_{\mathrm{F}} \%$ and $\Delta \mathrm{P}_{\mathrm{E}} \%$ were calculated for calm water conditions. The predicted $\Delta \mathrm{P}_{\mathrm{E}} \%$ was then, compared to an operational report showing the actual increases in effective power. The report was provided by a ship performance analysis company which performs computerised hydrodynamic performance analysis based on the actual vessel performance data acquired by the crew or 
monitoring systems. It was observed that $\Delta \mathrm{P}_{\mathrm{E}} \%$ prediction of model and $\Delta \mathrm{P}_{\mathrm{E}} \%$ calculation of company did not show a good agreement. This is due to the fact that the company report illustrates the average increase of $\mathrm{P}_{\mathrm{E}}$ over a certain selected time period rather than showing individual time dependent $\mathrm{P}_{\mathrm{E}}$ increases due to biofouling accumulation at each part of the operation. Therefore, a valid comparison was made between the averaged predicted $\Delta \mathrm{P}_{\mathrm{E}} \%$ and $\Delta \mathrm{P}_{\mathrm{E}} \%$ calculated by the company and results showed that the difference between those two was $\sim 4 \%$.

The predicted total fouling ratings were found to be $\sim 6.7$ for the operation used in the validation step and $\sim 50$ for the case study. The predictions made on SC of calcareous type fouling indicated that no calcareous type fouling occurred for both operations. The percentage increases in frictional resistance of the $176 \mathrm{~m}$ vessel were predicted to be $\sim 32 \%$ at a ship speed of 14 knots at the end of one-year long ship operation. These values changed to $\sim 43 \%$ in $\Delta \mathrm{C}_{\mathrm{F}}$ and $\sim 25 \%$ in $\Delta \mathrm{P}_{\mathrm{E}}$ for $258 \mathrm{~m}$ vessel at a design speed of 15 knots, respectively.

It is important to note that the model uses the roughness functions for specific fouling conditions which were provided in the literature. Without a doubt, these roughness conditions do not exactly represent the all fouling conditions during time-dependent biofouling growth. However, each fouling condition was represented by an appropriate roughness function with a predicted equivalent sand roughness height. As future work, it is of note that there are still needs to produce roughness functions of real-fouled surfaces to extend existing roughness function data in the literature.

The main advantage of the developed model is that as the developed model predicts timedependent increases in $\mathrm{P}_{\mathrm{E}}$ of the ship, it is effective to decide the best maintenance (drydocking) and/or hull cleaning intervals in order to operate ships in the most profitable and environmentally friendly way.

The authors are aware that the model has some assumptions and limitations originated from a lack of data and impracticability of modelling some certain effects on biofouling. These can be summarised as follows.

First, the authors believe that the ideal biofouling prediction model should have both static and dynamic immersion test data. The static field tests data can be used to model biofouling growth while a ship is stationary whereas dynamic field tests data can be used to model biofouling growth when the ship is cruising. Since there are no accessible dynamic test data, the model was developed based on the static field immersion tests to predict biofouling accumulation over the idle times during the ship operations. It is well-known that biofouling growth decreases with increased water speed after a certain limit. Therefore, it is reasonable to assume that biofouling growth during idle times overweighs the biofouling growth during cruising times. However, in case of having dynamic test data, biofouling growth prediction for the ship voyages could be estimated by inserting this data into the model.

Moreover, the authors believe that detachment process of fouling organisms due to environmental factors such as temperature, salinity and other species etc. have been captured via long term field test data. However, the main key parameter regarding to cleaning phenomenon is the ship speed. The adhesion strengths of fouling organisms and shear stresses on the ship hull due to ship speed should also be considered. The cleaning phenomenon was neglected as it is not realistic to reach to required shear stresses in order to overcome the adhesion strengths of biofouling organisms on biocidal antifouling coatings 
(Oliveira and Granhag, 2016). For these reasons also, the model at present is not/less suitable for use with coatings that heavily rely on fouling detachment processes, such as Foul-Release coatings.

Future work will concentrate on turning the developed model into a life-cycle assessment model, as proposed by Wang et al. (2018). Once the antifouling field test data are included in the model for different SPC type coating, the model will be capable of comparing different SPC type coatings in terms of fuel consumptions costs, incurred costs from paint application, ship maintenance costs, and more importantly GHG emissions. Then, it would be used as a decision-support tool in SPC type antifouling coating selection process for any ship, operating profile, and route in question.

\section{NOMENCLATURE}

\begin{tabular}{|c|c|}
\hline psu & Unit Of Salinity \\
\hline$v$ & Water Flow Velocity $(\mathrm{m} / \mathrm{s})$ \\
\hline$I$ & Light Intensity (cd) \\
\hline$S$ & Concentration Of Nutrients $\left(\mu \mathrm{mol} \mathrm{kg}^{-1}\right)$ \\
\hline$m_{t}$ & Microtexture \\
\hline$\sigma$ & Surface Potential (C. $\left.\mathrm{m}^{-2}\right)$ \\
\hline$\theta_{\mathrm{c}}$ & Contact Angle Of Surface (degree) \\
\hline $\mathrm{R}_{\mathrm{t}}$ & Surface Roughness $(\mu \mathrm{m})$ \\
\hline$\eta_{\mathrm{c}}$ & Antifouling Coating Performance Parameter \\
\hline$\mu$ & Specific Growth Rate \\
\hline$\eta_{\mathrm{cx}}$ & Antifouling Coating Performance Parameter At The Field Test Location X \\
\hline$\eta_{\text {cy }}$ & Antifouling Coating Performance Parameter At The Field Test Location Y \\
\hline$\eta_{\mathrm{ca}}$ & Antifouling Coating Performance Parameter At An Arbitrary Location \\
\hline$b$ and $f$ & Logistic Curve Regression Parameters For SC Of Calcareous Type Fouling \\
\hline $\mathrm{SC}$ & Surface Coverage $(\%)$ \\
\hline BG & Biofouling Growth \\
\hline API & Antifouling Performance Index \\
\hline FR & Fouling Rating \\
\hline $\mathrm{t}_{0}$ and $\tau$ & Antifouling Coating Regression Parameters \\
\hline$L$ & Ship Design Length (m) \\
\hline$B$ & Ship Design Breadth (m) \\
\hline$T$ & Ship Design Draft (m) \\
\hline$\Delta$ & Ship Design Displacement(tonnes) \\
\hline$V$ & Ship Design Speed (knot) \\
\hline$a$ & Regression Upper Limit \\
\hline$t$ & Idle Time Length (Hour/Day) \\
\hline$S S T$ & Sea Surface Temperature $\left(\mathrm{C}^{\circ}\right)$ \\
\hline$S S T_{y}$ & The Sea Surface Temperature At The Location $\mathrm{Y}\left(\mathrm{C}^{\circ}\right)$ \\
\hline$S S T_{x}$ & The Sea Surface Temperature At The Location $\mathrm{X}\left(\mathrm{C}^{\circ}\right)$ \\
\hline $\mathrm{SST}_{\mathrm{a}}$ & The Sea Surface Temperature At An Arbitrary Location $\left(\mathrm{C}^{\circ}\right)$ \\
\hline$t_{01}-t_{E 1}$ & Database First Period \\
\hline$t_{01}-t_{E 2}$ & Database Second Period \\
\hline
\end{tabular}




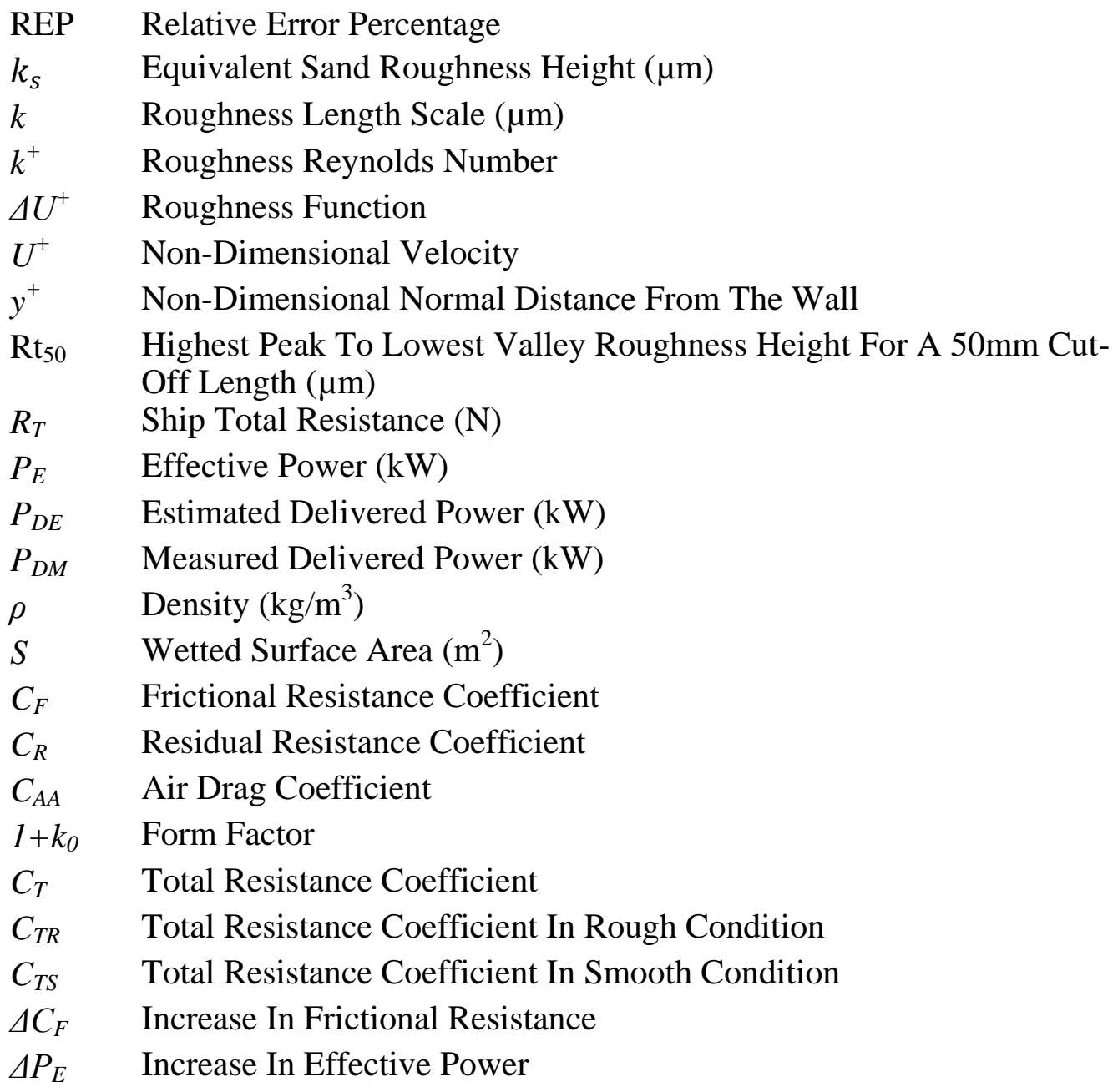

\section{ACKNOWLEDGEMENTS}

The authors are grateful for Carnegie Trust support as the research presented in this paper was generated as part of the project 'Time-Based Biofouling Model For Ships' funded by THE CARNEGIE TRUST FOR THE UNIVERSITIES OF SCOTLAND, Grant agreement number : RIG007452. The authors also gratefully acknowledge that the research presented in this paper was partially funded by Loyd Register (LR). 


\section{REFERENCES}

ASTM D3623-78a, 2012. Standard Test Method for Testing Antifouling Panels in Shallow Submergence.

ASTM D6990-05, 2011. Standard Practice for Evaluating Biofouling Resistance and Physical Performance of Marine Coating Systems.

Bijl, P.K., Schouten, S., Sluijs, A., Reichart, G.-J., Zachos, J.C., Brinkhuis, H., 2009. Early Palaeogene temperature evolution of the southwest Pacific Ocean. Nature 461, 776.

Braun-Blanquet, J., 1932. Plant Sociology. Mcgraw-Hill Book Company, Inc; New York; London.

Breur, H.J.A., 2001. Fouling and bioprotection of metals: Monitoring and control of deposition processes in aqueous environments, Applied Sciences. Delft University of Technology.

Candries, M., 2001. Drag, boundary layer and roughness characteristics of marine surfaces coated with antifoulings. University of Newcastle Upon Tyne, Newcastle.

Chambers, L.D., Stokes, K.R., Walsh, F.C., Wood, R.J.K., 2006. Modern approaches to marine antifouling coatings. Surface and Coatings Technology 201 (6), 3642-3652.

Coraddu, A., Gaggero, S., Villa, D., Figari, M., 2011a. A new approach in engine-propeller matching, Sustainable Maritime Transportation and Exploitation of Sea Resources. ROUTLEDGE in association with GSE Research, pp. 631-637.

Coraddu, A., Gualeni, P., Villa, D., 2011b. Investigation about wave profile effects on ship stability, Sustainable Maritime Transportation and Exploitation of Sea Resources. ROUTLEDGE in association with GSE Research, pp. 143-149.

Coraddu, A., Oneto, L., Baldi, F., Anguita, D., 2017. Vessels fuel consumption forecast and trim optimisation: A data analytics perspective. Ocean Engineering 130, 351-370.

Crisp, D.J., Bourget, E., 1985. Growth in Barnacles, in: Blaxter, J.H.S., Russell, F.S., Yonge, M. (Eds.), Advances in Marine Biology. Academic Press, pp. 199-244.

Cullimore, R.D., 1999. Microbiology of Well Biofouling, 1st ed.

Dafforn, K.A., Lewis, J.A., Johnston, E.L., 2011. Antifouling strategies: History and regulation, ecological impacts and mitigation. Marine Pollution Bulletin 62 (3), 453-465.

Darvehei, P., Bahri, P.A., Moheimani, N.R., 2018. Model development for the growth of microalgae: A review. Renewable and Sustainable Energy Reviews 97, 233-258.

de Castro, M.C.T., Vance, T., Yunnie, A.L.E., Fileman, T.W., Hall-Spencer, J.M., 2018. Low salinity as a biosecurity tool for minimizing biofouling on ship sea chests. Ocean Sci. 14 (4), 661-667. 
Demirel, Y.K., 2015. Modelling the roughness effects of marine coatings and biofouling on ship frictional resistance. The University of Strathclyde.

Demirel, Y.K., Turan, O., Incecik, A., 2017a. Predicting the effect of biofouling on ship resistance using CFD. Applied Ocean Research 62, 100-118.

Demirel, Y.K., Uzun, D., Zhang, Y., Fang, H.C., Day, A.H., Turan, O., 2017b. Effect of barnacle fouling on ship resistance and powering. Biofouling 33 (10), 819-834.

Demirel, Y.K., Song, S., Turan, O., Incecik, A., 2019. Practical added resistance diagrams to predict fouling impact on ship performance. Ocean Engineering 186, 106112.

Epelbaum, A., Herborg, L.M., Therriault, T.W., Pearce, C.M., 2009. Temperature and salinity effects on growth, survival, reproduction, and potential distribution of two nonindigenous botryllid ascidians in British Columbia. Journal of Experimental Marine Biology and Ecology 369 (1), 43-52.

Farhat, N.M., Vrouwenvelder, J.S., Van Loosdrecht, M.C.M., Bucs, S.S., Staal, M., 2016. Effect of water temperature on biofouling development in reverse osmosis membrane systems. Water Research 103, 149-159.

Fingerman, M., Nagabhushanam, R., Thompson, M.F., 1999. Recent advances in marine biotechnology. Science Publishers, Inc, Enfield, NH.

Gaggero, S., Villa, D., Brizzolara, S., 2010. RANS and PANEL method for unsteady flow propeller analysis. Journal of Hydrodynamics, Ser. B 22 (5), 564-569.

Granville, P.S., 1958. The frictional resistance and turbulent boundary layer of rough surfaces. Journal of ship research (2), 52-74.

Granville, P.S., 1987. Three indirect methods for the drag characterization of arbitrarily rough surfaces on flat plates, Proceedings of the Twenty-first American Towing Tank Conference. National Academies, p. 117.

Gregory, D.B., Bhushan, B., 2012. Biofouling: lessons from nature. Philosophical Transactions of the Royal Society A: Mathematical, Physical and Engineering Sciences 370 (1967), 2381-2417.

Guldhammer, H., Harvald, S.A., 1974. Ship Resistance : Effect of Form and Principle Dimensions. Akademisk Forlag, Copenhagen.

Hama, F.R., 1954. Boundary-layer characteristics for smooth and rough surfaces. Society of Naval Architects and Marine Engineers, New York.

Haslbeck, E.G., Bohlander, G.S., 1992. Microbial biofilm effects on drag-lab and field. Naval surface warfare center carderock div annapolis MD.

Howell, D., Behrends, B., 2006. A review of surface roughness in antifouling coatings illustrating the importance of cutoff length. Biofouling 22 (6), 401-410. 
Hundley, L.L., Tate Sr, C., 1980. Hull-fouling studies and ship powering trial results on seven FF 1052 class ships.

IMO, 2011. ANNEX 26,RESOLUTION MEPC.207(62),2011 Guidelines for the control and management of ships' Biofouling to minimize the transfer of Invasive Aquatic Species

ITTC, 1978. ITTC - Recommended Procedures 7.5 - 0203 - 01.4, Performance, Propulsion 1978 ITTC Performance Prediction Method

Kempf, G., 1937. On the effect of roughness on the resistance of ships. Trans INA (79), 109119.

Kerr, A., Hodgkiess, T., Cowling, M.J., Beveridge, C.M., Smith, M.J., Parr, A.C.S., 1998. A novel technique to prevent bacterial fouling, using imposed surface potential. Journal of Applied Microbiology 85 (6), 1067-1072.

Kiil, S., Yebra, D.M., 2009. 14 - Modelling the design and optimization of chemically active marine antifouling coatings, in: Hellio, C., Yebra, D. (Eds.), Advances in Marine Antifouling Coatings and Technologies. Woodhead Publishing, pp. 334-364.

Kroeker, K.J., Kordas, R.L., Crim, R., Hendriks, I.E., Ramajo, L., Singh, G.S., Duarte, C.M., Gattuso, J.-P., 2013. Impacts of ocean acidification on marine organisms: quantifying sensitivities and interaction with warming. Global Change Biology 19 (6), 1884-1896.

Lehaitre, M., Delauney, L., Compère, C., 2008. in: Babin, M., Roesler, C.S., Cullen, J.J. (Eds.), Real-time coastal observing systems for marine ecosystem dynamics and harmful algal blooms: theory, instrumentation and modelling. Unesco Publishing.

Lindholdt, A., Dam-Johansen, K., Yebra, D.M., Olsen, S.M., Kiil, S., 2015. Estimation of long-term drag performance of fouling control coatings using an ocean-placed raft with multiple dynamic rotors. Journal of Coatings Technology and Research 12 (6), 975-995.

Lord, J.P., 2017. Impact of seawater temperature on growth and recruitment of invasive fouling species at the global scale. Marine Ecology 38 (2), e12404.

Lützen, M., Kristensen, H.O.H., 2012. A model for prediction of propulsion power and emissions-tankers and bulk carriers, World maritime technology conference.

McDonald, M.R., McClintock, J.B., Amsler, C.D., Rittschof, D., Angus, R.A., Orihuela, B., Lutostanski, K., 2009. Effects of ocean acidification over the life history of the barnacle Amphibalanus amphitrite. Marine Ecology Progress Series 385, 179-187.

Milne, A., 1990. Roughness and drag from the marine paint chemist's viewpoint., Marine Roughness and Drag Workshop, London.

Monty, J.P., Dogan, E., Hanson, R., Scardino, A.J., Ganapathisubramani, B., Hutchins, N., 2016. An assessment of the ship drag penalty arising from light calcareous tubeworm fouling. Biofouling 32 (4), 451-464. 
Munk, T., Kane, D., Yebra, D.M., 2009. 7 - The effects of corrosion and fouling on the performance of ocean-going vessels: a naval architectural perspective, in: Hellio, C., Yebra, D. (Eds.), Advances in Marine Antifouling Coatings and Technologies. Woodhead Publishing, pp. 148-176.

Oliveira, D., Granhag, L., 2016. Matching Forces Applied in Underwater Hull Cleaning with Adhesion Strength of Marine Organisms. Journal of Marine Science and Engineering 4 (4).

Owen, D., Demirel, Y.K., Oguz, E., Tezdogan, T., Incecik, A., 2018. Investigating the effect of biofouling on propeller characteristics using CFD. Ocean Engineering 159, 505-516.

Pielke, R.A., 2012. Sea Surface Temperature Trends As A Function Of Latitude Bands By Roger A. Pielke Sr. and Bob Tisdale, Climate Science: Roger Pielke Sr.

Qiu, J.-W., Qian, P.-Y., 1998. Combined effects of salinity and temperature on juvenile survival, growth and maturation in the polychaete Hydroides elegans. Marine Ecology Progress Series 168, 127-134.

Railkin, A.I., 2004. Marine biofouling colonization processes and defenses. CRC Press, Boca Raton, FL.

Sánchez, A., Yebra, D.M., 2009. 16 - Ageing tests and long-term performance of marine antifouling coatings, in: Hellio, C., Yebra, D. (Eds.), Advances in Marine Antifouling Coatings and Technologies. Woodhead Publishing, pp. 393-421.

Sarkar, S., 2005. Ecology, in: Zalta, E.N. (Ed.), Stanford Encyclopedia of Philosophy, Winter 2016 ed. Metaphysics Research Lab.

Scardino, A.J., Guenther, J., de Nys, R., 2008. Attachment point theory revisited: the fouling response to a microtextured matrix. Biofouling 24 (1), 45-53.

Schultz, M.P., 2004. Frictional Resistance of Antifouling Coating Systems. Journal of Fluids Engineering 126 (6), 1039-1047.

Schultz, M.P., 2007. Effects of coating roughness and biofouling on ship resistance and powering. Biofouling 23 (5-6), 331-341.

Schultz, M.P., Bendick, J.A., Holm, E.R., Hertel, W.M., 2011. Economic impact of biofouling on a naval surface ship. Biofouling 27 (1), 87-98.

Schultz, M.P., Swain, G.W., 2000. The influence of biofilms on skin friction drag. Biofouling 15 (1-3), 129-139.

Silva, E.R., Ferreira, O., Ramalho, P.A., Azevedo, N.F., Bayón, R., Igartua, A., Bordado, J.C., Calhorda, M.J., 2019. Eco-friendly non-biocide-release coatings for marine biofouling prevention. Science of The Total Environment 650, 2499-2511.

Song, S., Demirel, Y.K., Atlar, M., 2019. An investigation into the effect of biofouling on the ship hydrodynamic characteristics using CFD. Ocean Engineering 175, 122-137. 
Swain, G.W., Kovach, B., Touzot, A., Casse, F., Kavanagh, C.J., 2007. Measuring the Performance of Today's Antifouling Coatings. Journal of Ship Production 23 (3), 164-170.

Takahashi, T., Sutherland, S.C., Chipman, D.W., Goddard, J.G., Ho, C., Newberger, T., Sweeney, C., Munro, D.R., 2014. Climatological distributions of $\mathrm{pH}$, pCO2, total CO2, alkalinity, and $\mathrm{CaCO} 3$ saturation in the global surface ocean, and temporal changes at selected locations. Marine Chemistry 164, 95-125.

Tezdogan, T., Demirel, Y.K., 2014. An owerview of marine corrosion protection with a focus on cathodic protection and coatings. Brodogradnja (65), 49-59.

Tezdogan, T., Demirel, Y.K., Kellett, P., Khorasanchi, M., Incecik, A., Turan, O., 2015. Fullscale unsteady RANS CFD simulations of ship behaviour and performance in head seas due to slow steaming. Ocean Engineering 97, 186-206.

Thiyagarajan, V., Harder, T., Qian, P.-Y., 2003. Combined effects of temperature and salinity on larval development and attachment of the subtidal barnacle Balanus trigonus Darwin. Journal of Experimental Marine Biology and Ecology 287 (2), 223-236.

Turan, O., Demirel, Y.K., Day, S., Tezdogan, T., 2016. Experimental Determination of Added Hydrodynamic Resistance Caused by Marine Biofouling on Ships. Transportation Research Procedia 14, 1649-1658.

Uzun, D., Zhang, Y., Demirel, Y.K., Turan, O., 2017. Experimental Determination of Added Resistance of Barnacle Fouling on Ships by Using 3D Printed Barnacles, The Fifth International Conference on Advanced Model Measurement Technology for The Maritime Industry, Glasgow,UK.

Villanueva, V.D., Font, J., Schwartz, T., Romaní, A.M., 2011. Biofilm formation at warming temperature: acceleration of microbial colonization and microbial interactive effects. Biofouling 27 (1), 59-71.

Wang, H., Oguz, E., Jeong, B., Zhou, P., 2018. Life cycle cost and environmental impact analysis of ship hull maintenance strategies for a short route hybrid ferry. Ocean Engineering $161,20-28$.

Woods Hole Oceanographic Institute, 1952. Marine fouling and its prevention. United States Naval Institute. 